\title{
Applying Game-Based Approaches for Physical Rehabilitation of Poststroke Patients: A Systematic Review
}

\author{
Soheila Saeedi (D, Marjan Ghazisaeedi (D), and Sorayya Rezayi (i) \\ Health Information Management Department, School of Allied Medical Sciences, Tehran University of Medical Sciences, \\ Tehran, Iran \\ Correspondence should be addressed to Sorayya Rezayi; s_rezayi@razi.tums.ac.ir
}

Received 21 March 2021; Revised 15 June 2021; Accepted 31 July 2021; Published 15 September 2021

Academic Editor: Redha Taiar

Copyright () 2021 Soheila Saeedi et al. This is an open access article distributed under the Creative Commons Attribution License, which permits unrestricted use, distribution, and reproduction in any medium, provided the original work is properly cited.

\begin{abstract}
Objective. A large number of patients need critical physical rehabilitation after the stroke. This study aimed to review and report the result of published studies, in which newly emerged games were employed for physical rehabilitating in poststroke patients. Materials and Methods. This systematic review study was performed based on the PRISMA method. A comprehensive search of PubMed, Scopus, IEEE Xplore Digital Library, and ISI Web of Science was conducted from January 1, 2014, to November 9, 2020, to identify related articles. Studies have been entered in this review based on inclusion and exclusion criteria, in which new games have been used for physical rehabilitation. Results. Of the 1326 retrieved studies, 60 of them met our inclusion criteria. Virtual reality-oriented games were the most popular type of physical rehabilitation approach for poststroke patients. “The Nintendo Wii Fit" game was used more than other games. The reviewed games were mostly operated to balance training and limb mobilization. Based on the evaluation results of the utilized games, only in three studies, applied games were not effective. In other studies, games had effective outcomes for target body members. Conclusions. The results indicate that modern games are efficient in poststroke patients' physical rehabilitation and can be used alongside conventional methods.
\end{abstract}

\section{Introduction}

Stroke is one of the diseases that can lead to disability and affect people's daily activities and lead to reduced performance [1]. According to the Global Burden of Diseases (GBD 2010), stroke is the second most common cause of death worldwide [2]. In 2010, the number of people with the first stroke was 16.9 million, and people who died of stroke was 5.9 million [2]. Disability-adjusted life years (DALYs) lost also was 102 million, and the number of stroke survivors was 33 million [2]. Ninety percent of stroke survivors have a disability in one of their functions [3]. Most people with poststroke disability experience changes in emotional function, limb movement, balance, and muscle strength, and there is a risk of falling for these patients in performing ordinary activities, all of which affect the quality of life of survivors [4]. The main treatment solution to reduce functional defects after stroke is rehabilitation [5]. Poststroke physical rehabilitation in common is a gradual process that can take months or even years, and these patients require multiple sessions of treatment.

However, patients may not be able to attend these treatment sessions for rehabilitation fully. Several factors may lead to limited access to these treatment sessions, including the following: difficulty accessing a physiotherapist by the patient, high cost of attending the treatment session, patient's age and disability, the long distance that the patient has to travel, or poor patient compliance [6]. One of the solutions that can be offered to overcome these problems is to do rehabilitation activities at home; for rehabilitation exercises to be effective at home, high-intensity methods focused on specific repetitions of the practice with the feedback of performance should be used [7]. Consequently, one of the innovative methods that can obviate the above 
problems is applying modern games; these games have been used in various fields, including education, public policy, and healthcare [8]. Furthermore, they can also be utilized as a support tool for rehabilitation activities and provide an enjoyable environment for patients and increase adherence to treatment sessions $[9,10]$.

As it turns out, various studies have been performed to determine the effectiveness of the mentioned games. A systematic review study by Primack et al. found that games improved $69 \%$ of psychological therapy outcomes, $46 \%$ of clinician skills outcomes, $42 \%$ of health education outcomes, and $37 \%$ of disease self-management outcomes [11]. Another study examined the games managed for rehabilitation in respiratory conditions and concluded these games were effective $[12,13]$. The purpose of this study is reviewing, summarizing, and reporting studies in which modern games have been used for physical rehabilitation of poststroke patients and tries to answer the following questions:

(1) Which type of games is the most used?

(2) Which gamification approaches have been used to improve the performance of poststroke patients?

(3) What was the most common type of physical rehabilitation in stroke survivors?

(4) What are the evaluation results of games used in poststroke patients?

\section{Research Methodology}

This systematic review was conducted based on Preferred Reporting Items for Systematic Reviews and MetaAnalyzes (PRISMA) checklist to ensure inclusion of relevant studies [14].

2.1. Design. In this review, a systematic search of scientific databases including ISI Web of Science, PubMed, IEEE Xplore Digital Library, and Scopus was performed from January 1, 2014, to November 9, 2020. The comprehensive search strategy comprised a set of main keywords from PubMed Mesh terms and Emtree related to "game," "rehabilitation," and "poststroke" patients. The specific detail of main applied keywords for each database is presented in Table 1.

2.2. Inclusion and Exclusion Criteria for Study Selection. The extracted studies were included if they fulfilled the following criteria: (1) original articles and proceedings, (2) the focus of this review was on only physical rehabilitation innovative game-based solutions for poststroke physical disabilities, (3) one of the gamification techniques was employed for physical rehabilitation or disability treatment, (4) in this study, the result of using different games and outcomes of video games or immersive-oriented approaches on physical rehabilitation were reviewed, and (5) studies were limited to those published in the English language. Besides, the studies were excluded if they met the following criteria: (1) the title, abstract, or full text of the article that did not relate to video games, virtual, or mixed reality-based games, (2) studies which were review or meta-analysis, book chapters, letter, reports, and technical reports, (3) articles in which the result of applying games was not reported quantitatively, (4) articles about cognitive rehabilitation, and (4) non-English published ones.

2.3. Literature Refinement. In comprehensive and scientific databases searching, 833 studies were retrieved after duplicate removal. Some inclusion and exclusion criteria were set for the study selecting phase. In the first phase, two independent reviewers (SS and SR) specified the primary classification of included studies; then, they synthesized selected citations' critical features. MG validated the primarily determined classifications. All titles and abstracts of extracted studies were investigated and screened based on the research questions and unique aims to select relevant ones by two reviewers under MG's supervision. In the last phase, citations that met inclusion and exclusion criteria were selected to enter the full-text review phase. The fulltexts of relevant studies were screened by SS and SR thoroughly. Key characteristics were entered into a spreadsheet in Excel for each study. Two authors (SR and SS) independently extracted the study characteristics based on the predefined classifications. For reaching an agreement, the information was examined again by two authors. The next reviewer (MG) evaluated and validated all of the obtained results. EndNote X9 was used for resource management, and all qualitative analyses were performed in SPSS v20. The main classifications of screened citations are shown in Figure 1.

\section{Results}

The flow of screening articles based on the PRISMA method is shown in Figure 2. Prior scientific searches assigned 833 citations after the duplicate removal phase. Next, 41 studies were eliminated due to their irrelevancy in the full-text screening phase. In the last screening step, 60 studies were included based on our main study objectives as eligible studies. Based on the predefined classification elements, a summary of the key results is described in Table 2.

3.1. Study Characteristics. The reviewed studies in this study were published in 53 journals and 7 international conferences. All the names of journals and conferences are listed in Table 3 based on their frequency. As it is clear, the "Archives of Physical Medicine and Rehabilitation," "Clinical Rehabilitation," "Games for Health Journal: Research, Development, and Clinical Applications," and "Journal of Stroke and Cerebrovascular Diseases" have the first rank with 5 or 4 published studies among journals. The distribution of studies by year and country of publication is presented in Table 4. As it is conducted, the majority of citations were published in 2019. Accordingly, in different countries, innovative physical rehabilitation solutions were employed and Korea with 13 citations had the highest number of studies. 
TABLE 1: Search strategy for each database.

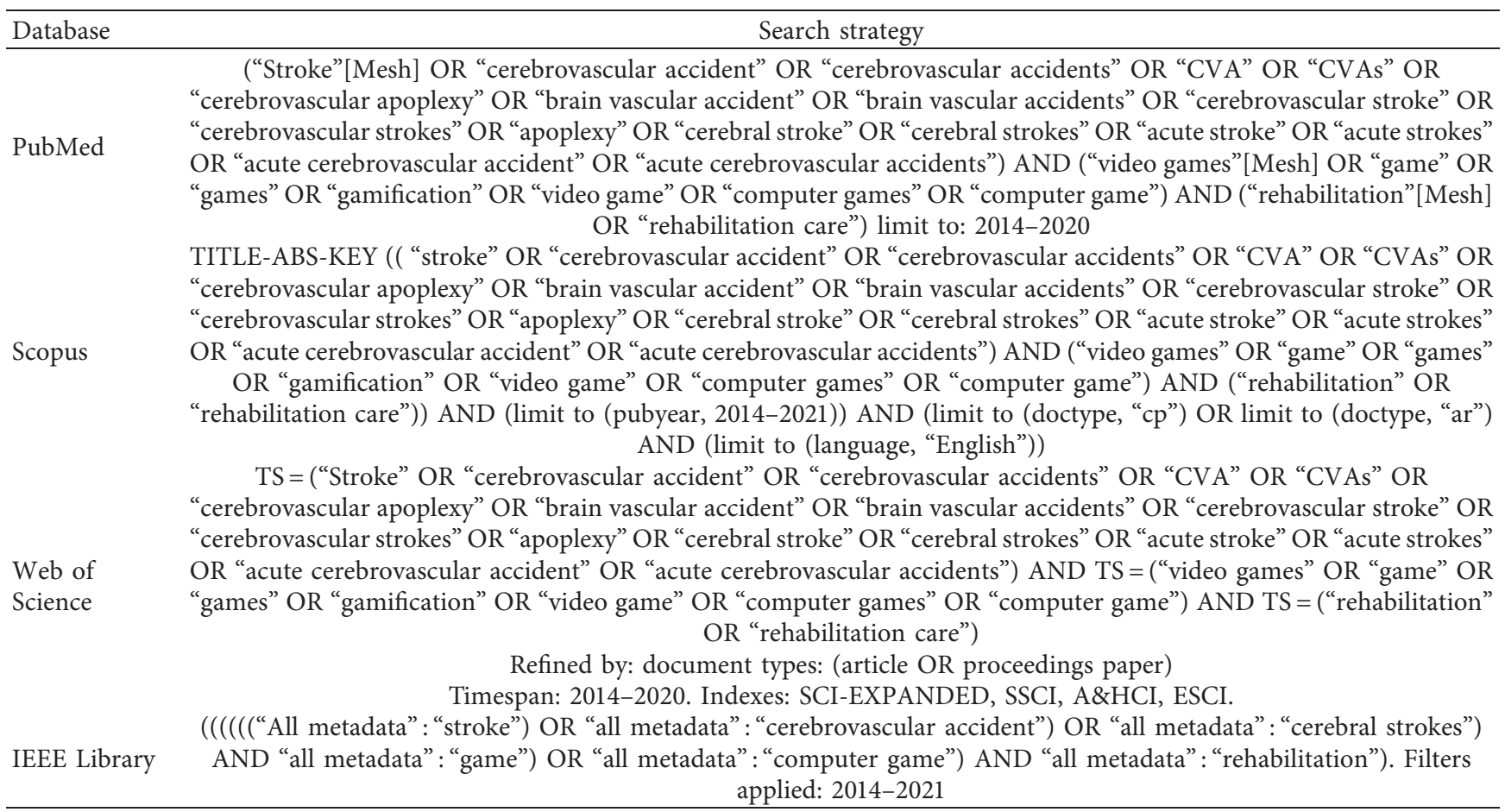

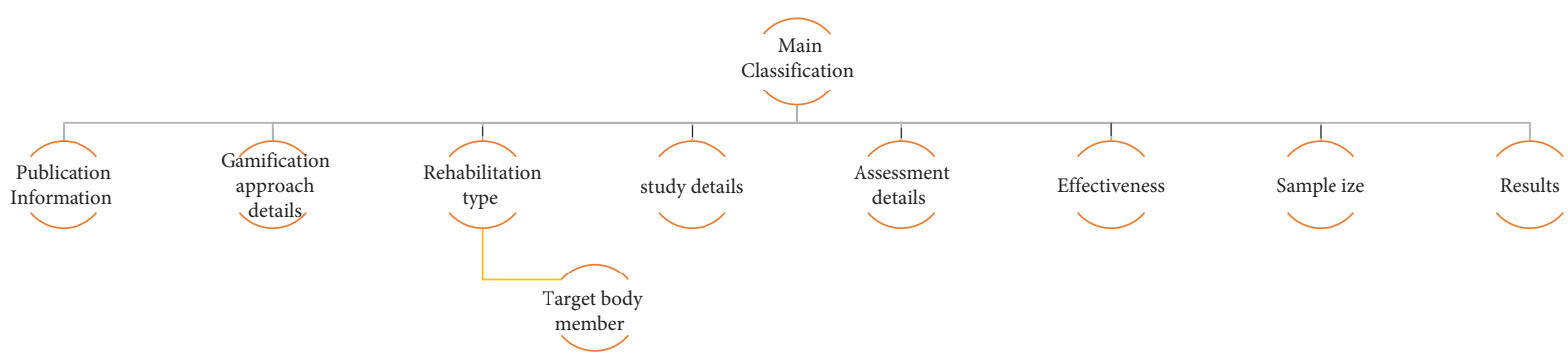

Figure 1: The key classification of relevant studies.

3.2. The Distribution of Literature by Main Gamification Types and Approaches. Based on analysis, virtual reality-oriented games and video games are the most popular physical rehabilitation types for poststroke patients. The distribution of reviewed literature based on the type of games is shown in Figure 3. Besides, it turns out "Microsoft Xbox 360 Kinect" and "the Nintendo Wii Fit" approaches have been the widest utilized game-based tools that have been extracted in studies (Figure 4).

The deployment platform for most of the studies included in this review $(n=28,46.66 \%)$ was Nintendo and Microsoft Xbox 360 Kinect.

There are many games in the field of rehabilitation that researchers and therapists can use for rehabilitating patients. However, in this systematic review, most studies have used existing games in rehabilitation and do not develop games for the purpose of research that we can refer to the Nintendo Wii Fit, Microsoft Xbox 360 Kinect games, Peggle, IREX, and HTC Vive games.
3.3. Distribution of Studies Based on Type of Physical Rehabilitation. The critical types of physical rehabilitation therapies applied for poststroke patients based on different games were divided into several main categories. The most important types of rehabilitation are "Balance training," "Mobilization of the limbs," and "Muscular strengthening" (Figure 5).

3.4. Distribution of Studies Based on Type of Studies, Sample Size, and Session Detail. In the investigated studies, three types of intervention studies and their effectiveness have been utilized (Table 5). The sample size from minimum to maximum number is 5 people in 2 studies and 209 people in one study. The highest frequency for the selected sample size was 10 people, which is in 4 studies. The lowest age of the recruited subjects in studies was 24 years on average, and the highest mean of age was 72 years old. In most studies, the number of males included in the intervention was higher than females; in 4 studies, the exact number of genders was not reported. 


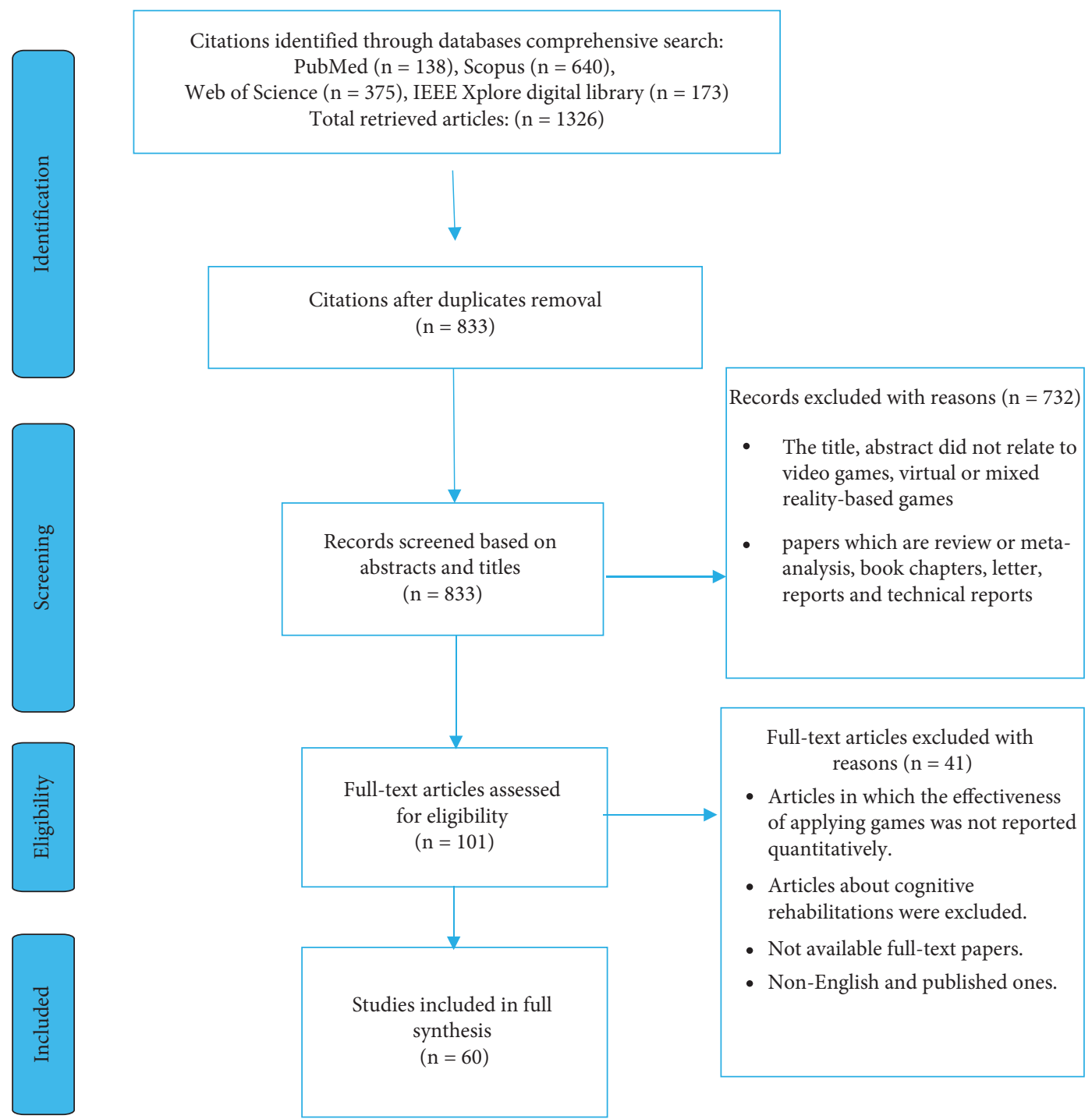

FIGURE 2: The PRISMA diagram for the records search and study selection.

The frequency of physical rehabilitation time (by unit time) is shown in Figure 6. In this study, the length of rehabilitation time is converted to hour to compare the treatment time in different studies. In studies, the minimum duration of treatment to provide rehabilitation is one hour; besides, 10, 9, and 12 hours is the highest frequency of treatment time in studies, which was intended in a total of 12 studies.

\subsection{Distribution of Studies Based on Assessment Scores.} According to the results of reviewed different studies, numerous indicators and tests have been applied to evaluate physical rehabilitation outcomes in poststroke patients. In other words, according to the type of rehabilitation treatment provided to patients, different indicators and metrics have been calculated to assess the condition of the rehabilitated organs of the body (before and after the intervention). For this reason, we were unable to compare the assessment scores calculated during the intervention.
However, considering how many indicators and metrics in each study were affected by physical rehabilitation during the intervention treatment, we added a brief assessment from the authors' perspective. At the end of the intervention, if all indicators of functional or physical appraisal of patients are affected by game-based rehabilitation and a significant difference is seen, then we have labeled this rehabilitation approach "Effective." If only one or two of the several evaluation metrics are not affected by game-based rehabilitation, then we label them "Partly effective." Finally, if there is no significant difference in all evaluation measures before and after the intervention, we label them "No effective." In the following, the distribution of the reviewed studies based on effectiveness is shown in Figure 7.

\section{Discussion}

This survey's main objective was to review the studies in which games were applied for improving the physical functions and rehabilitation of poststroke patients. 


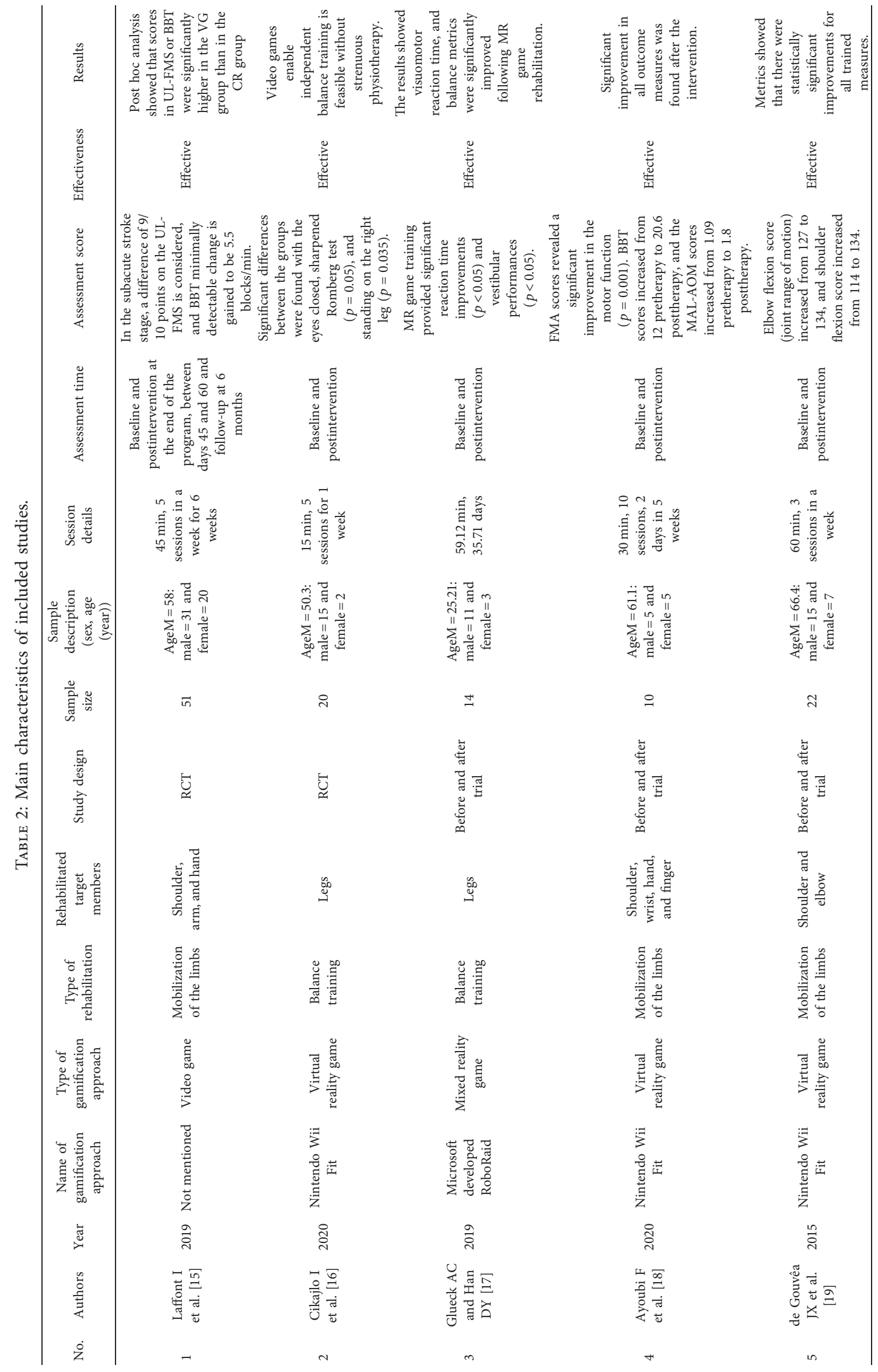




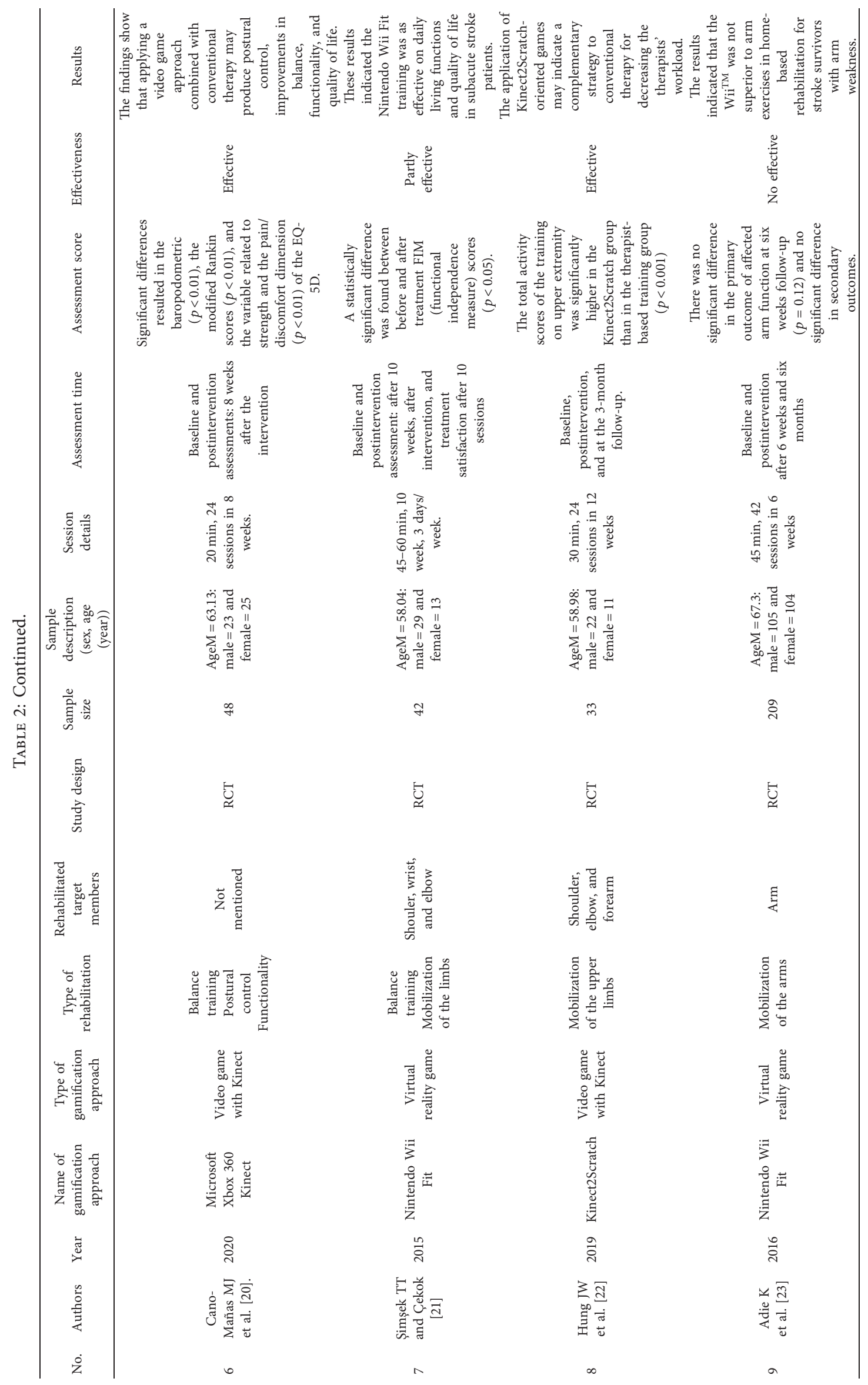




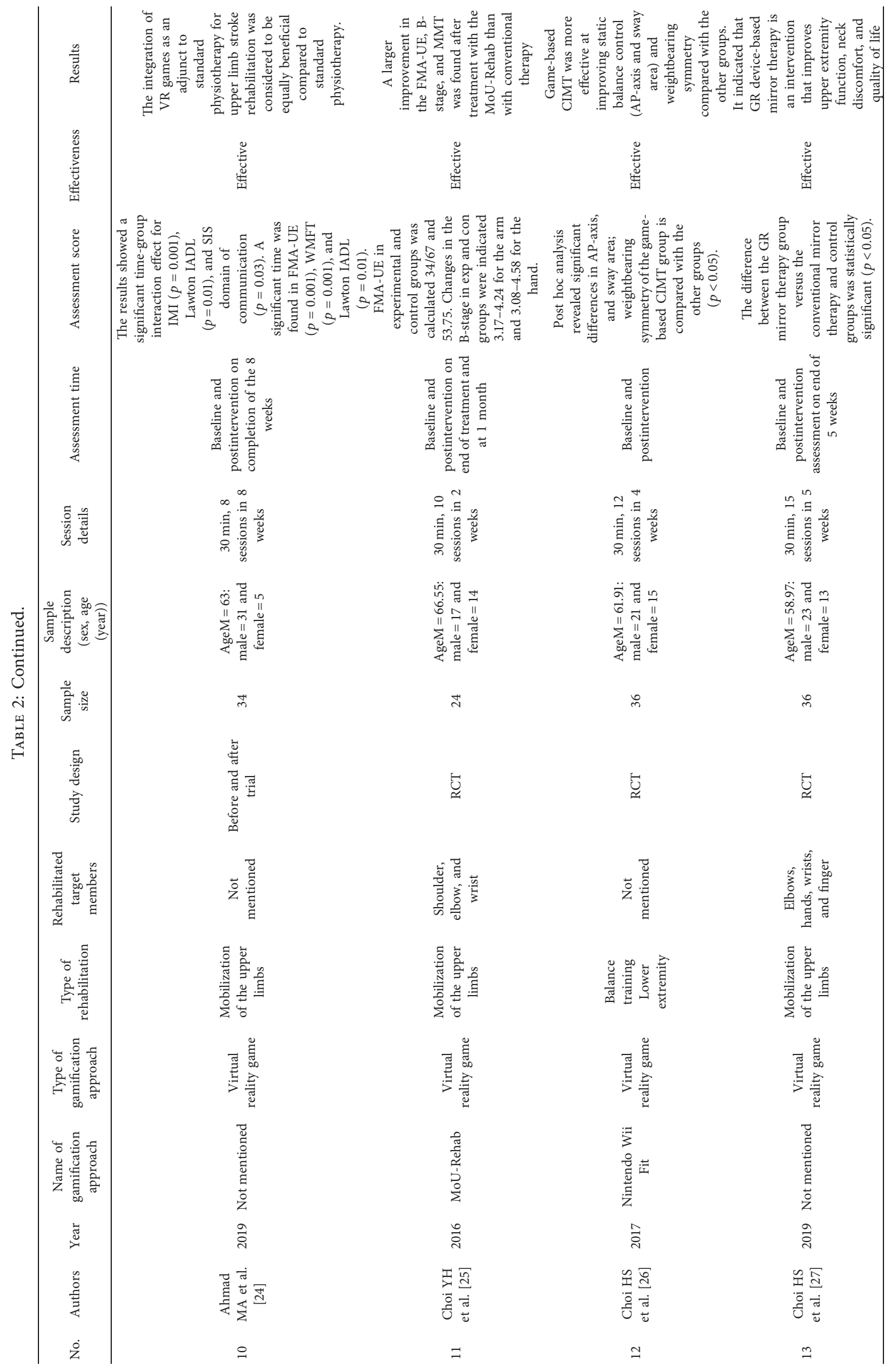




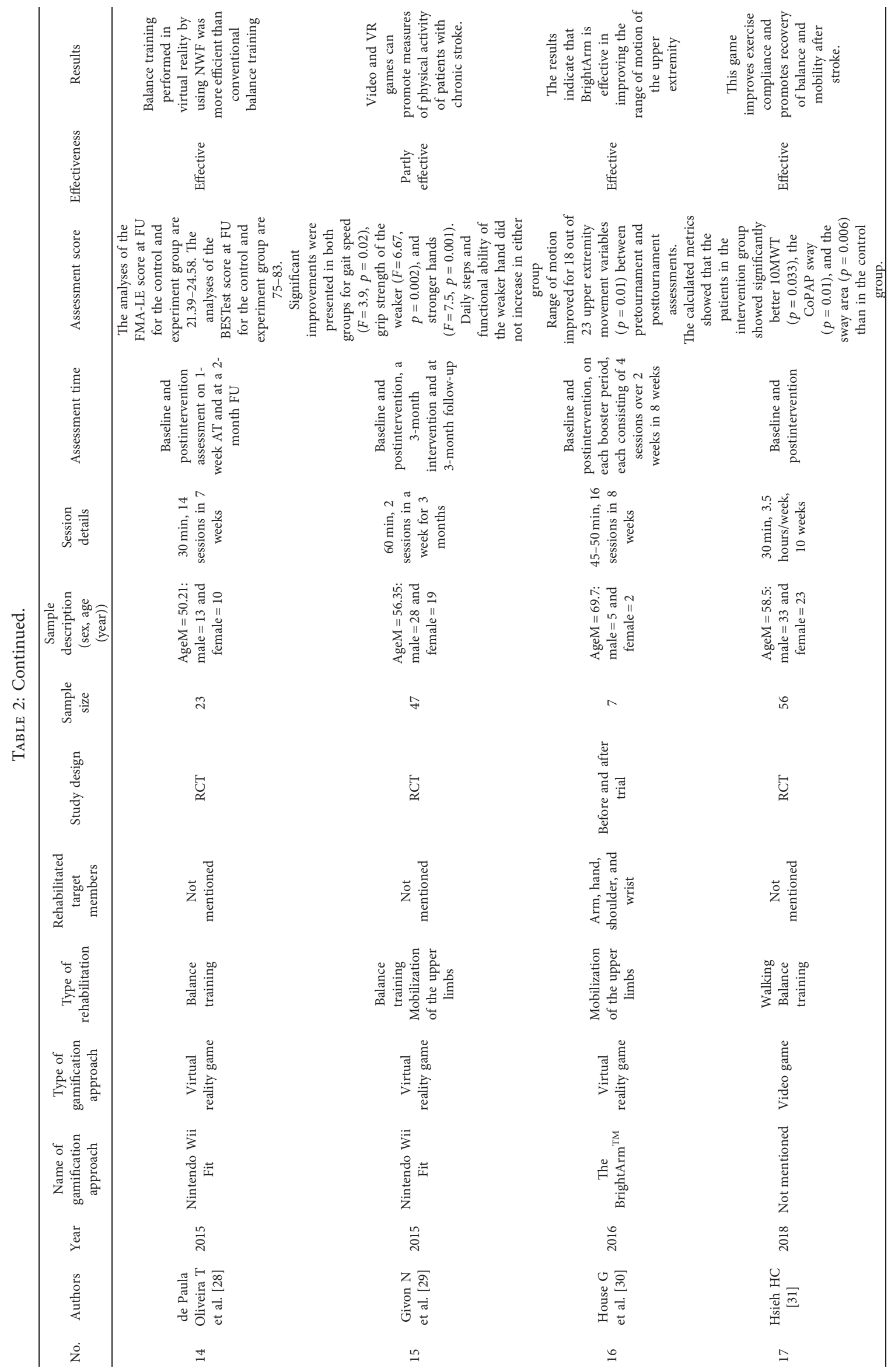




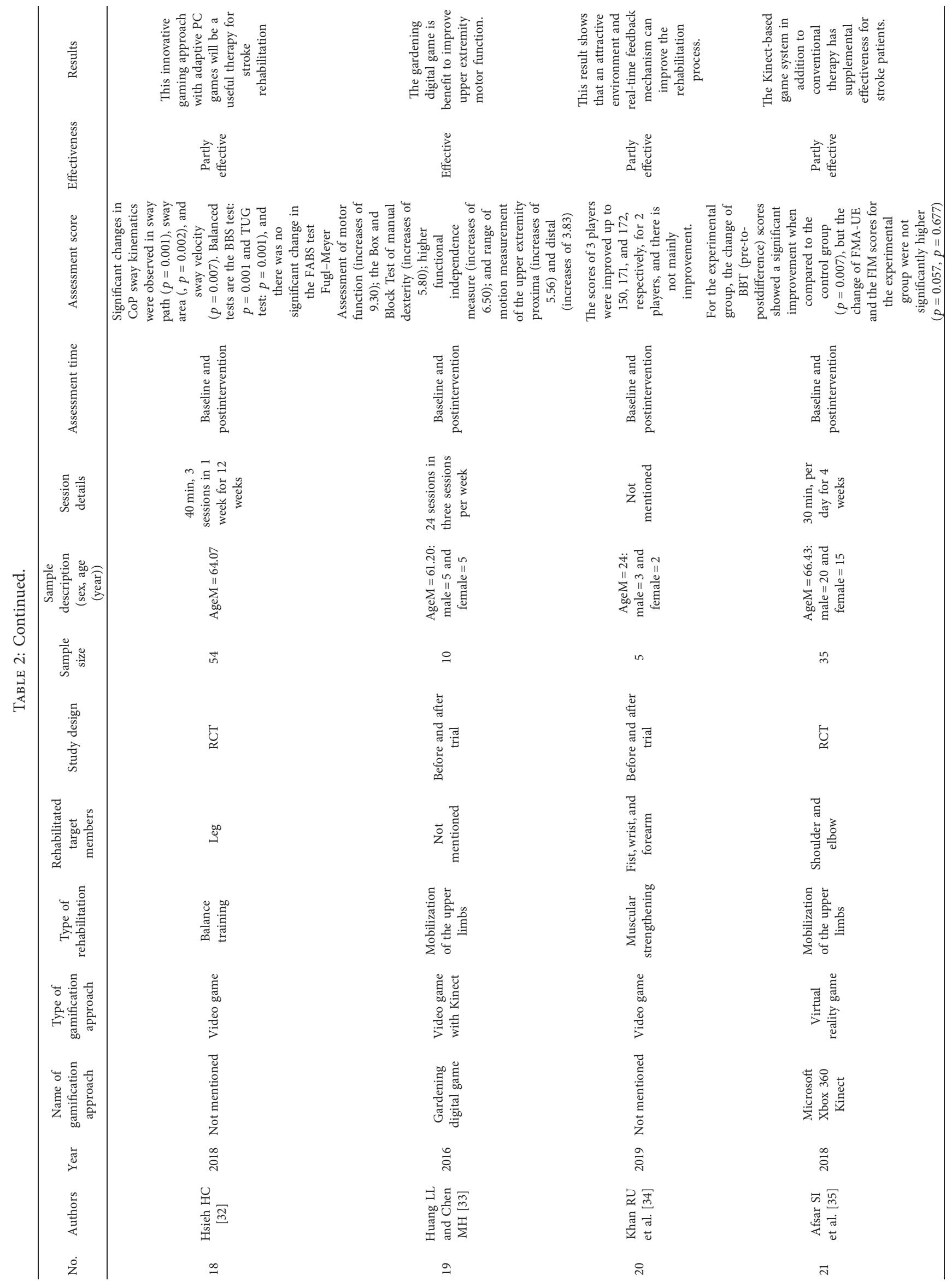




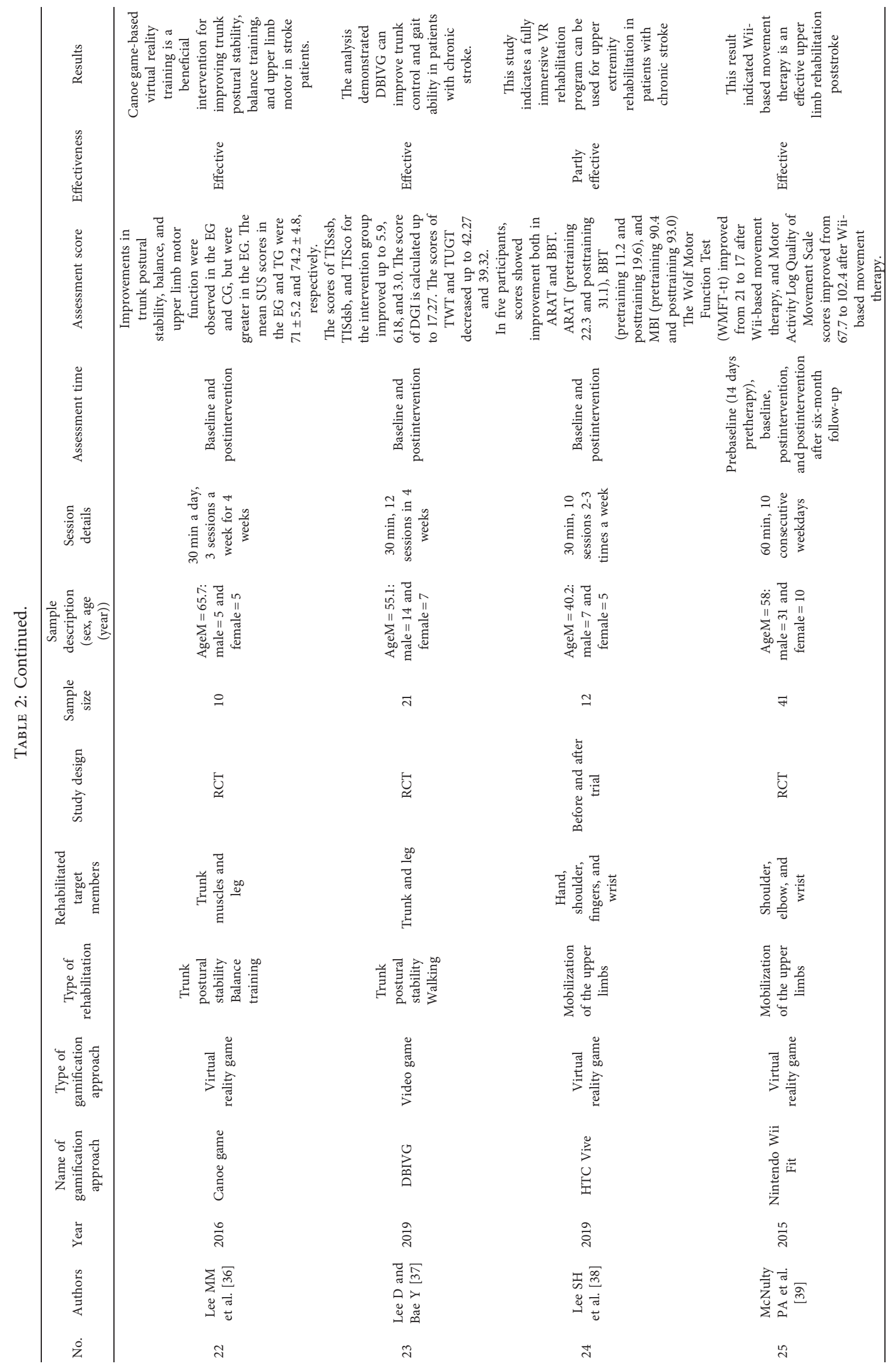




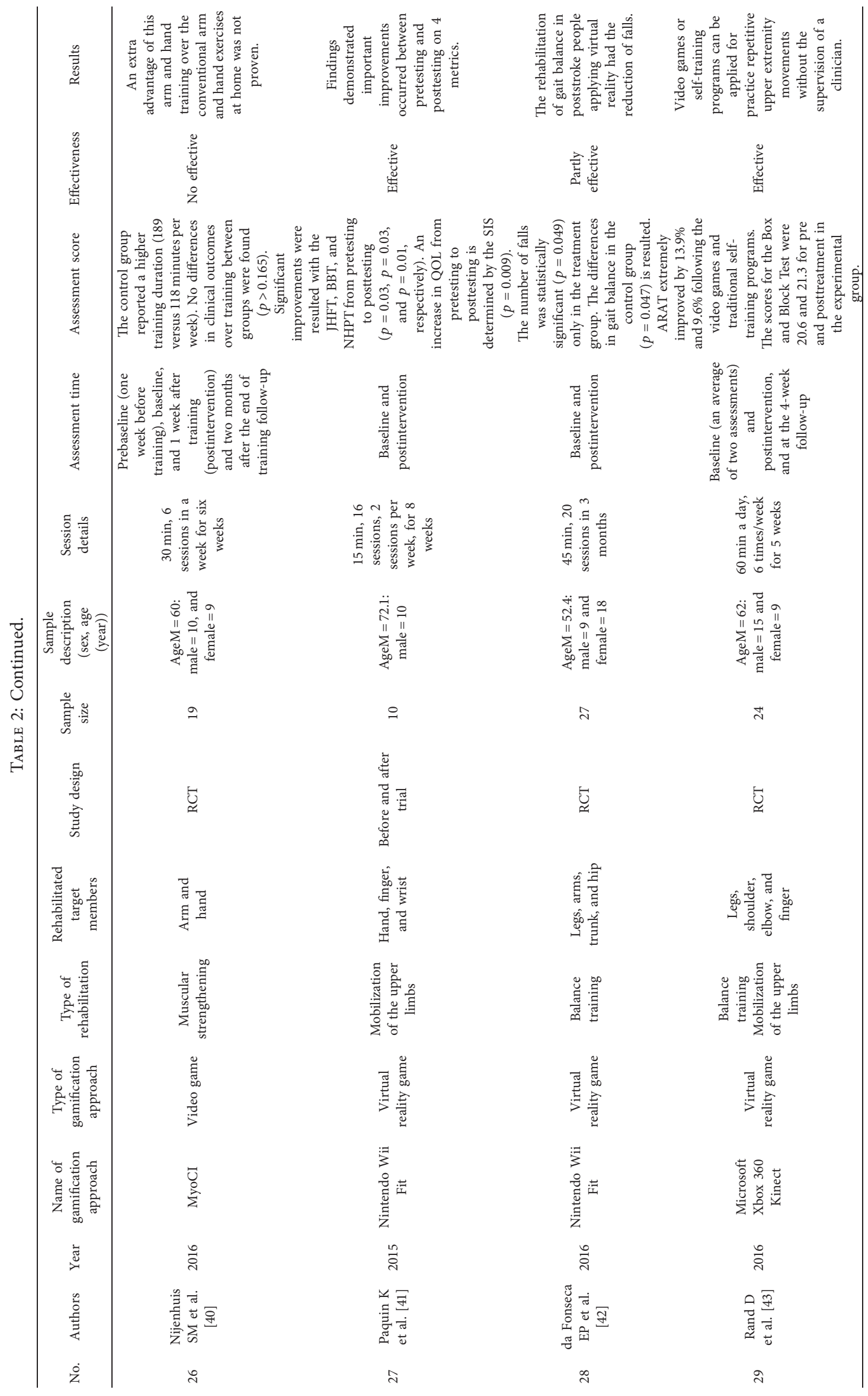




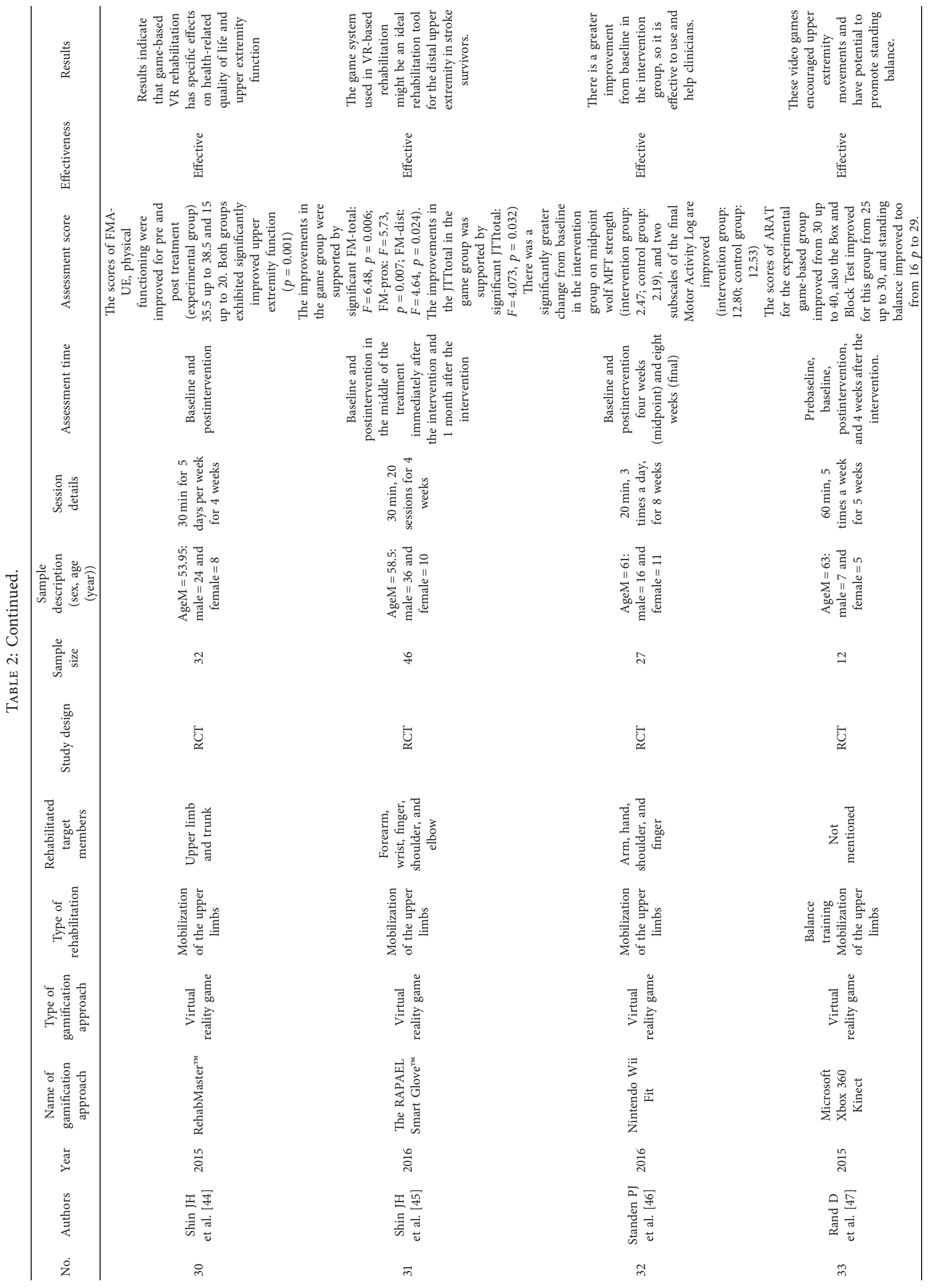




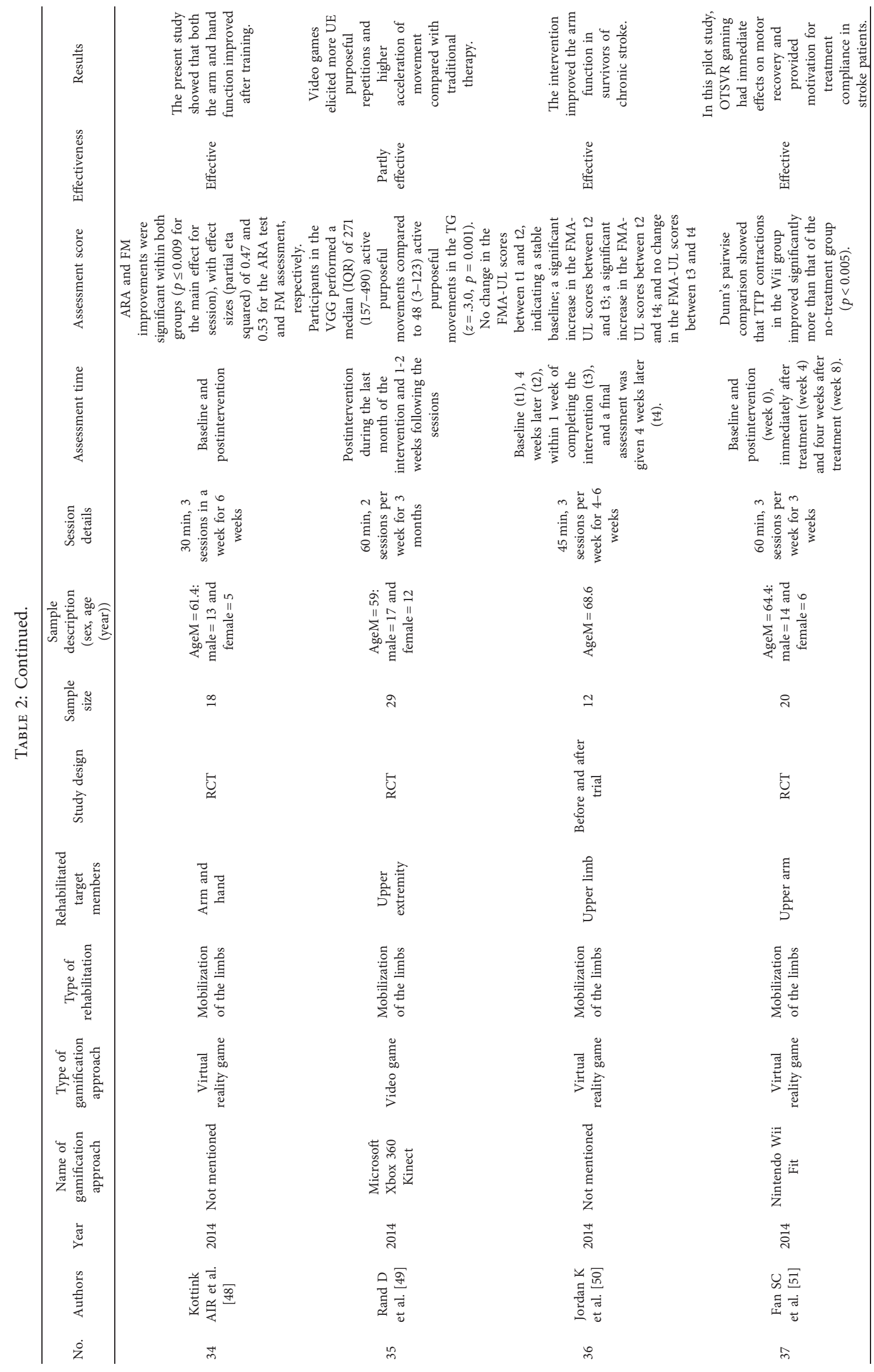




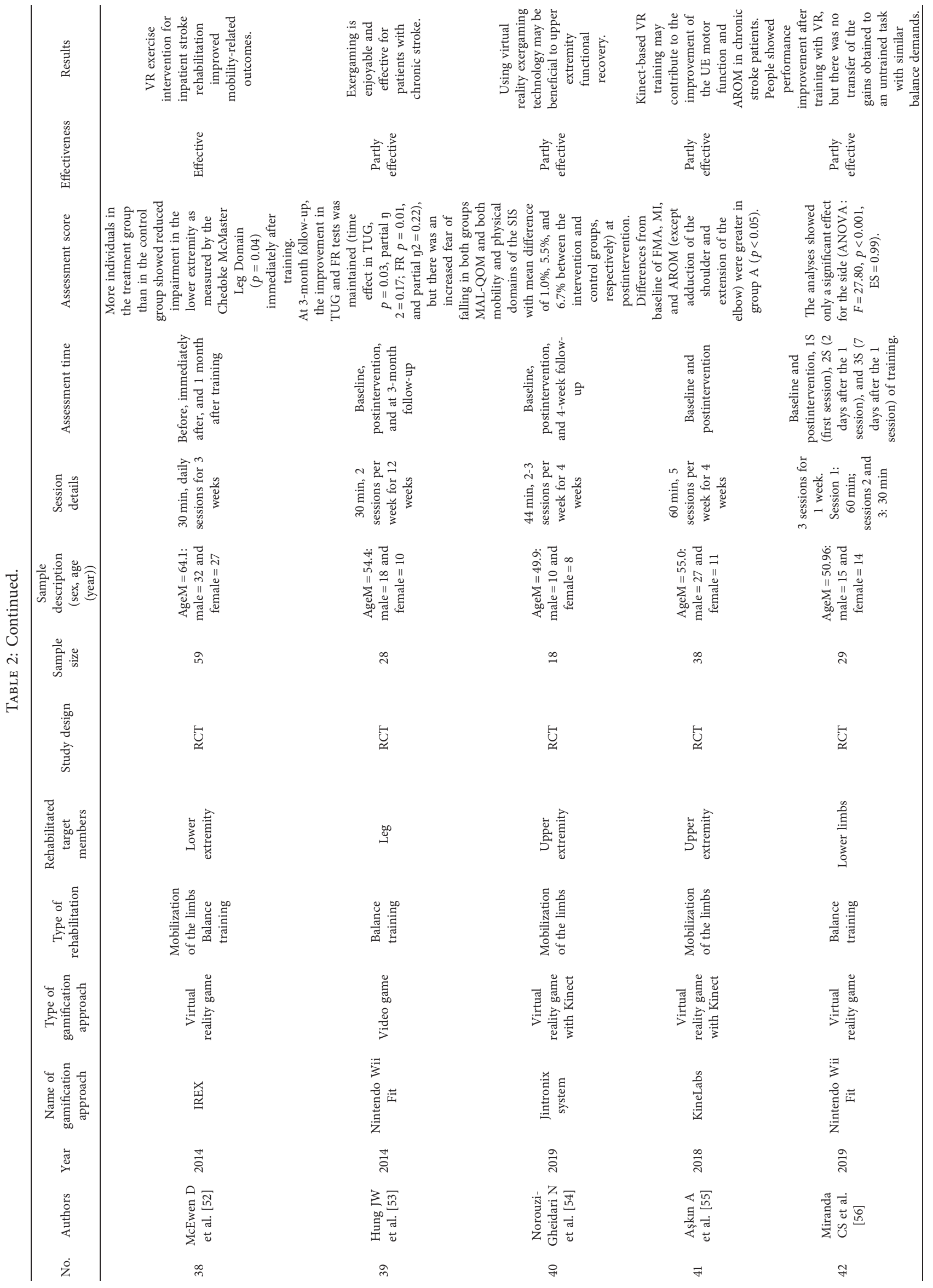




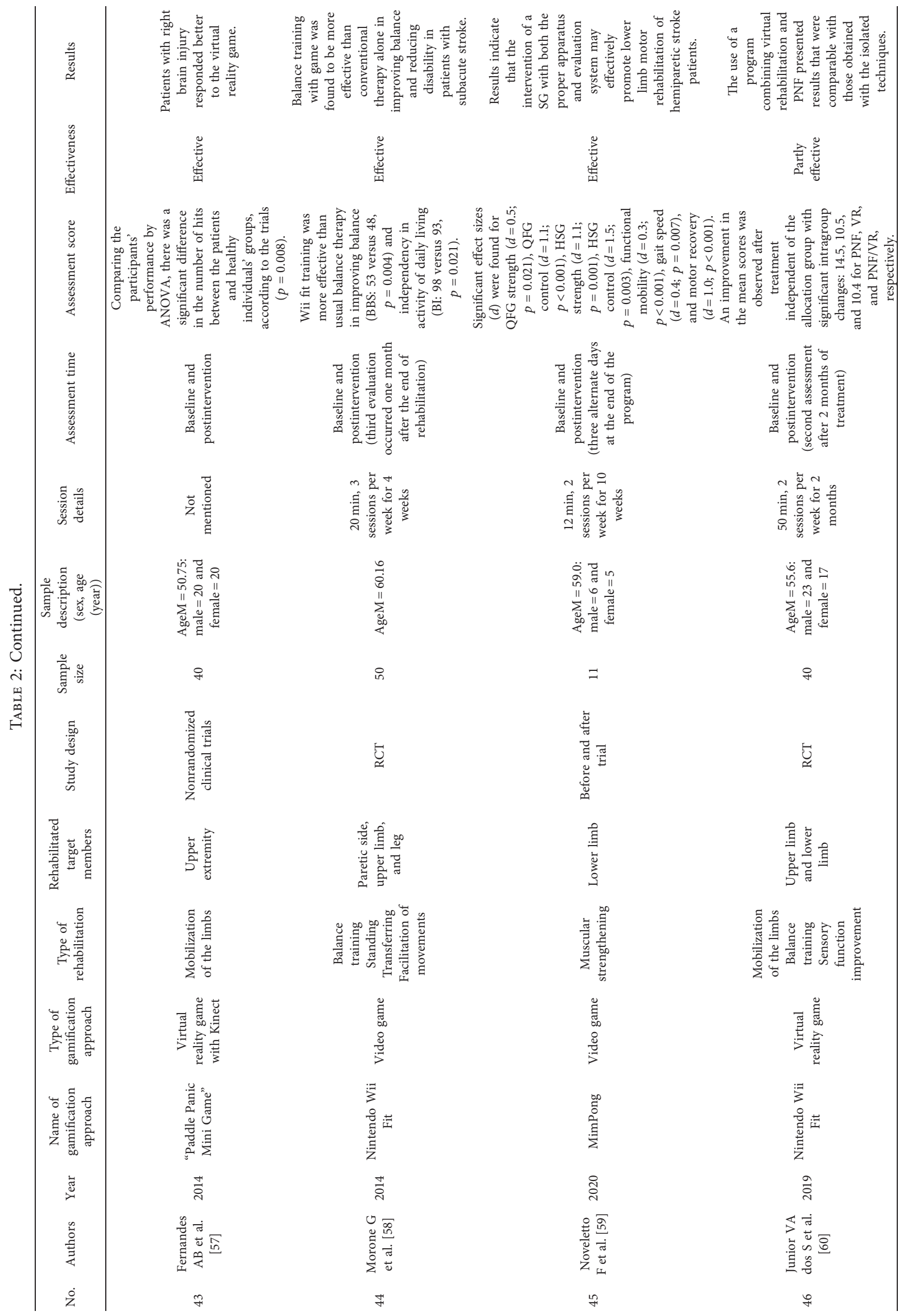




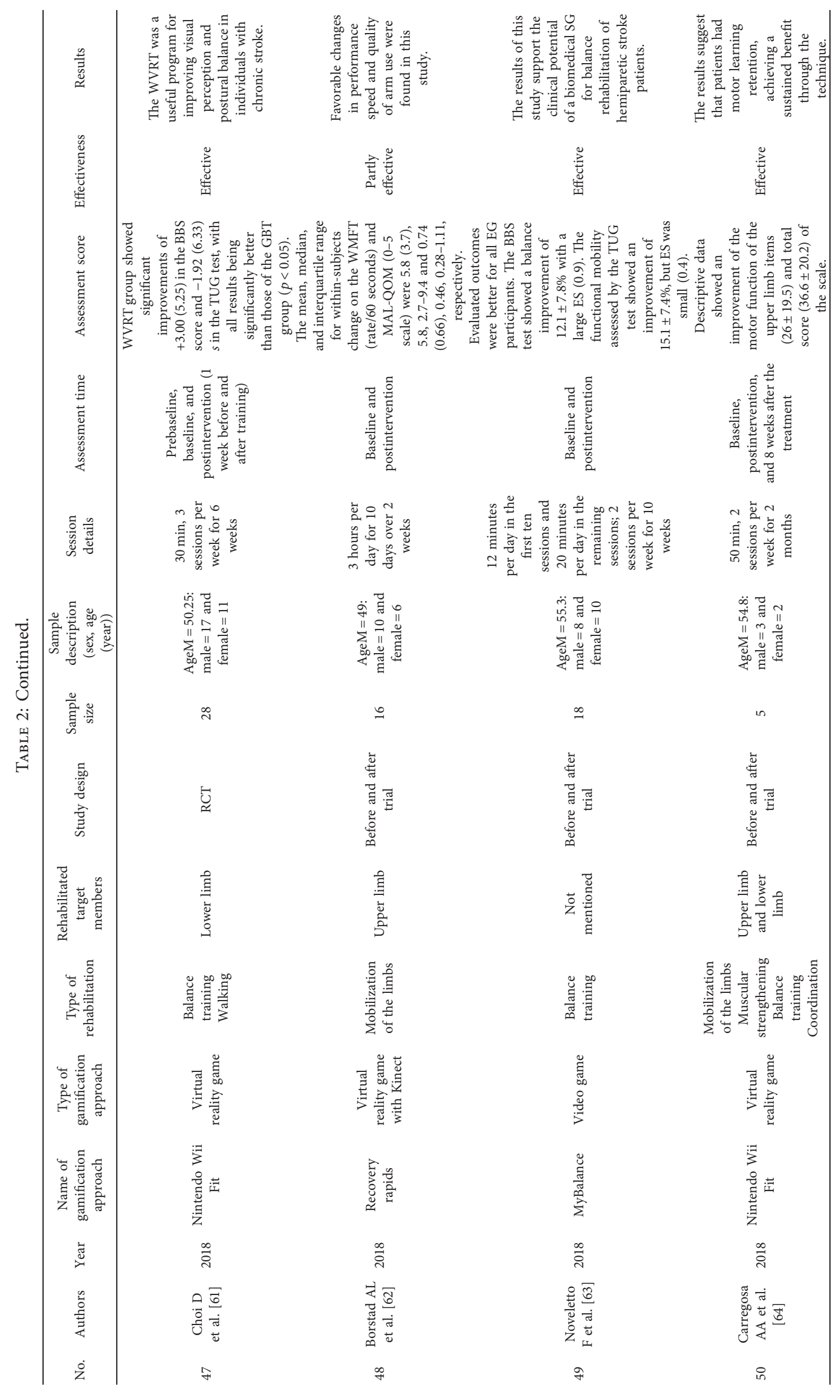




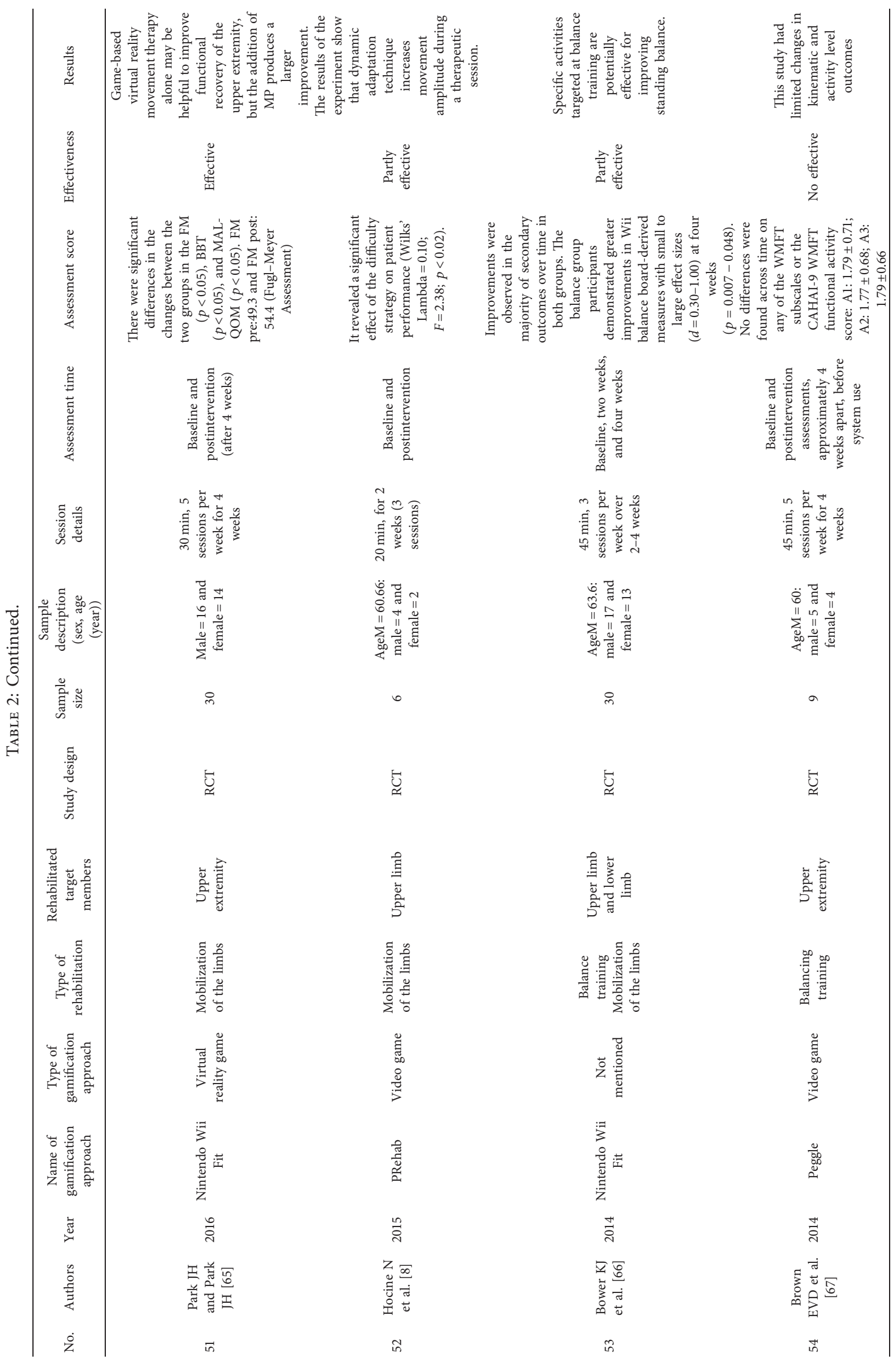




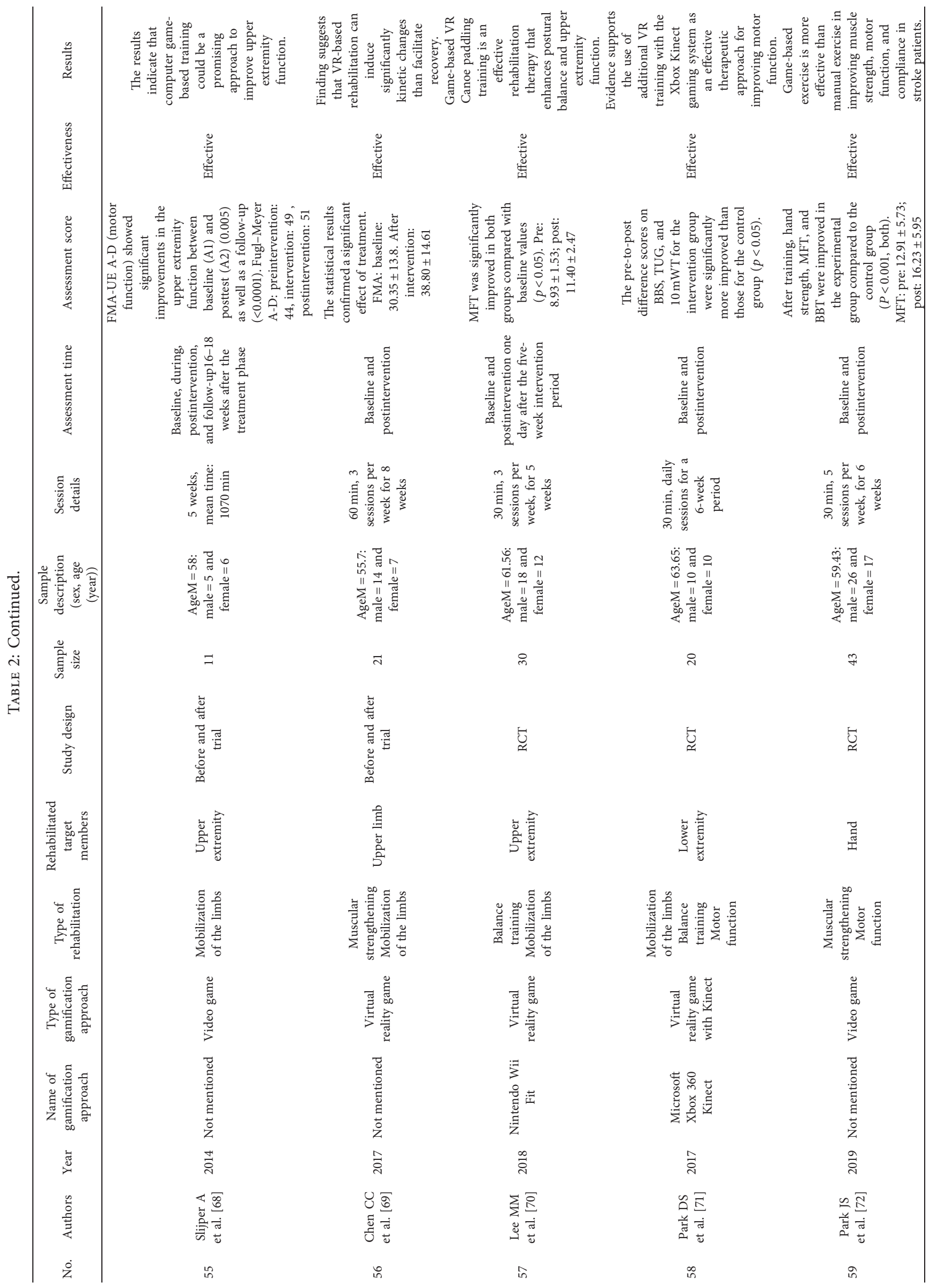




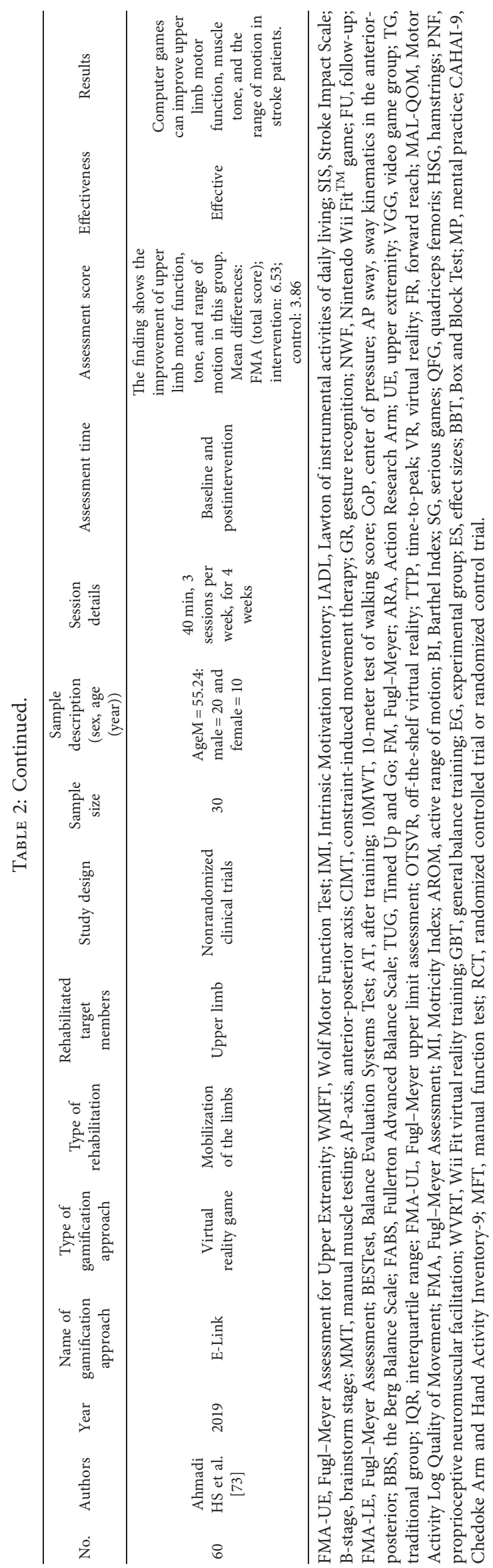


TABLE 3: Distribution of studies based on publication type.

\begin{tabular}{|c|c|c|}
\hline Journal/conference name & Conference & Journal \\
\hline Clinical Rehabilitation & & 5 \\
\hline Journal of Stroke and Cerebrovascular Diseases & & 4 \\
\hline Archives of Physical Medicine and Rehabilitation & & 4 \\
\hline Games for Health Journal: Research, development, and clinical applications & & 4 \\
\hline Disability and Rehabilitation & & 2 \\
\hline Journal of NeuroEngineering and Rehabilitation & & 2 \\
\hline NeuroRehabilitation & & 2 \\
\hline IEEE Transactions on Neural Systems and Rehabilitation Engineering & & 2 \\
\hline International Journal of Environmental Research and Public Health & & 2 \\
\hline Journal of Medical and Biological Engineering & & 1 \\
\hline International Medical Journal of Experimental and Clinical Research & & 1 \\
\hline American Journal of Physical Medicine and Rehabilitation & & 1 \\
\hline Computers in Biology and Medicine & & 1 \\
\hline Journal of Central Nervous System Disease & & 1 \\
\hline BioMed Research International & & 1 \\
\hline Brain Impairment & & 1 \\
\hline European Journal of Physical and Rehabilitation Medicine & & 1 \\
\hline User Modeling and User-Adapted Interaction & & 1 \\
\hline Frontiers in Psychology & & 1 \\
\hline Iranian Rehabilitation Journal & & 1 \\
\hline Journal of Physical Therapy Science & & 1 \\
\hline Journal of Healthcare Engineering & & 1 \\
\hline Annals of Physical and Rehabilitation Medicine & & 1 \\
\hline Journal of Motor Behavior & & 1 \\
\hline American Academy of Physical Medicine and Rehabilitation & & 1 \\
\hline Journal of Patient-Centered Research and Reviews & & 1 \\
\hline Restorative Neurology and Neuroscience & & 1 \\
\hline Stroke & & 1 \\
\hline Medical Science Monitor & & 1 \\
\hline Neurorehabilitation and Neural Repair & & 1 \\
\hline Somatosensory and Motor Research & & 1 \\
\hline The Journal of Physical Therapy Science & & 1 \\
\hline International Journal of Stroke & & 1 \\
\hline Virtual Reality & & 1 \\
\hline International Journal of Neuroscience & & 1 \\
\hline In Proceedings of the 3rd 2015 Workshop on ICTs for improving Patients Rehabilitation Research Techniques & 2 & \\
\hline Proceedings of the IEEE International Conference on Advanced Materials for Science and Engineering & 1 & \\
\hline In 2019 International Conference on Robotics and Automation in Industry & 1 & \\
\hline 2019 Fifth International Conference on Advances in Biomedical Engineering (ICABME) & 1 & \\
\hline International Conference on Virtual Rehabilitation & 1 & \\
\hline 2017 International Conference on Applied System Innovation (ICASI) & 1 & \\
\hline Total & 7 & 53 \\
\hline
\end{tabular}

According to results, emerging games possess the capacity and potential to rehabilitate physical aspects in poststroke patients; furthermore, these games can help patients improve their independence. According to surveys, virtual reality-based approaches and "the Nintendo Wii Fit" games were used more than other games. The most common use of games in poststroke survivors' rehabilitation was related to limb movement and balance training.

Due to the included studies' results, different indicators and scales have been calculated and statistically analyzed to evaluate and test game-based physical rehabilitation therapies for poststroke patients. These statistical analyses demonstrated the positive effect of innovative rehabilitation is provided in the form of games for these patients. Even in many studies, applied games in different environments (virtual reality, and video-based games) have led to a great improvement in patients' physical problems such as balance disorder, upper extremity spasticity, and limbs' immobility and muscular weakness [3, 5, 11, 74-77]. Researchers in these studies have concluded that they can incorporate these games into the treatment plan and physiotherapy of poststroke patients and use them as alternative therapies to traditional methods because, in these experimental studies, significant improvements in all outcome measures were found after the intervention $[76,78]$. However, in infrequent articles, no significant differences can be observed in all assessment scales (baseline and post-intervention assessments in the experimental and control groups) to evaluate game-oriented physiotherapies' effectiveness. For this reason, in these studies, the researcher has concluded that the 
TABLE 4: Distributions of studies of publication years and country.

\begin{tabular}{|c|c|c|c|c|c|c|c|c|c|}
\hline \multirow{2}{*}{ Row labels } & \multicolumn{9}{|c|}{ Column labels } \\
\hline & 2013 & 2014 & 2015 & 2016 & 2017 & 2018 & 2019 & 2020 & Total \\
\hline Australia & & 1 & 1 & & & & & & 2 \\
\hline Brazil* & & 1 & 2 & 1 & & 2 & 2 & 1 & 9 \\
\hline Canada & & 1 & 1 & & & & 1 & & 3 \\
\hline China & & & & 1 & & & & & 1 \\
\hline France & & & 1 & & & & 1 & & 2 \\
\hline Iran & & & & & & & 1 & & 1 \\
\hline Israel & & 1 & 2 & 1 & & & & & 4 \\
\hline Italy & & 1 & & & & & & 1 & 2 \\
\hline Lebanon & & & & & & & & 1 & 1 \\
\hline Malaysia & & & & & & & 1 & & 1 \\
\hline Netherlands & & 1 & & 1 & & & & & 2 \\
\hline New Zealand & & 1 & & & & & & & 1 \\
\hline Pakistan & & & & & & & 1 & & 1 \\
\hline Republic of Korea* & & & 1 & 4 & 2 & 2 & 4 & & 13 \\
\hline Spain & & & & & & & & 1 & 1 \\
\hline Sweden & & 1 & & & & & & & 1 \\
\hline Taiwan* & 1 & 1 & & & 1 & 2 & 1 & & 6 \\
\hline Turkey & & & 1 & & & 2 & & & 3 \\
\hline UK & & & & 2 & & & & & 2 \\
\hline USA & & 1 & & 1 & & 1 & 1 & & 4 \\
\hline Grand total & 1 & 10 & 9 & 11 & 3 & 9 & 13 & 4 & 60 \\
\hline
\end{tabular}

* 3 countries with the highest number of study prints.

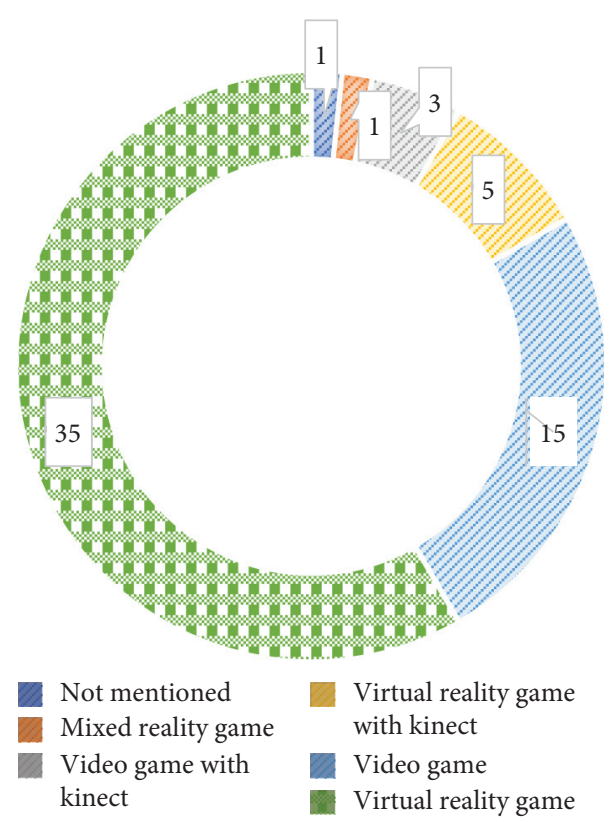

Figure 3: The distribution of studies based on gamification types.

game chosen to rehabilitate poststroke patients cannot be a useful tool to alternate with the traditional physical rehabilitation methods, and applying them can destroy the patient's time and motivation.

The reason for the ineffectiveness of newly emerged games for motor rehabilitation of stroke patients can have different reasons as follows: insufficient session times and training duration to generate consistent improvements in all patients, the insufficient number of participants in the experimental studies (randomized trails would require at least
25 participants in each group) $[38,76]$, the high mean age of patients in both intervention and control groups (underlying disability of people due to their age), and excessive movement limitations of the patients recruited in the study $[79,80]$.

According to this study's results, the most popular type of game for physical rehabilitation of poststroke patients was virtual reality games. Virtual reality-based games allow patients to interact with a virtual environment while performing rehabilitation exercises and simulating real 


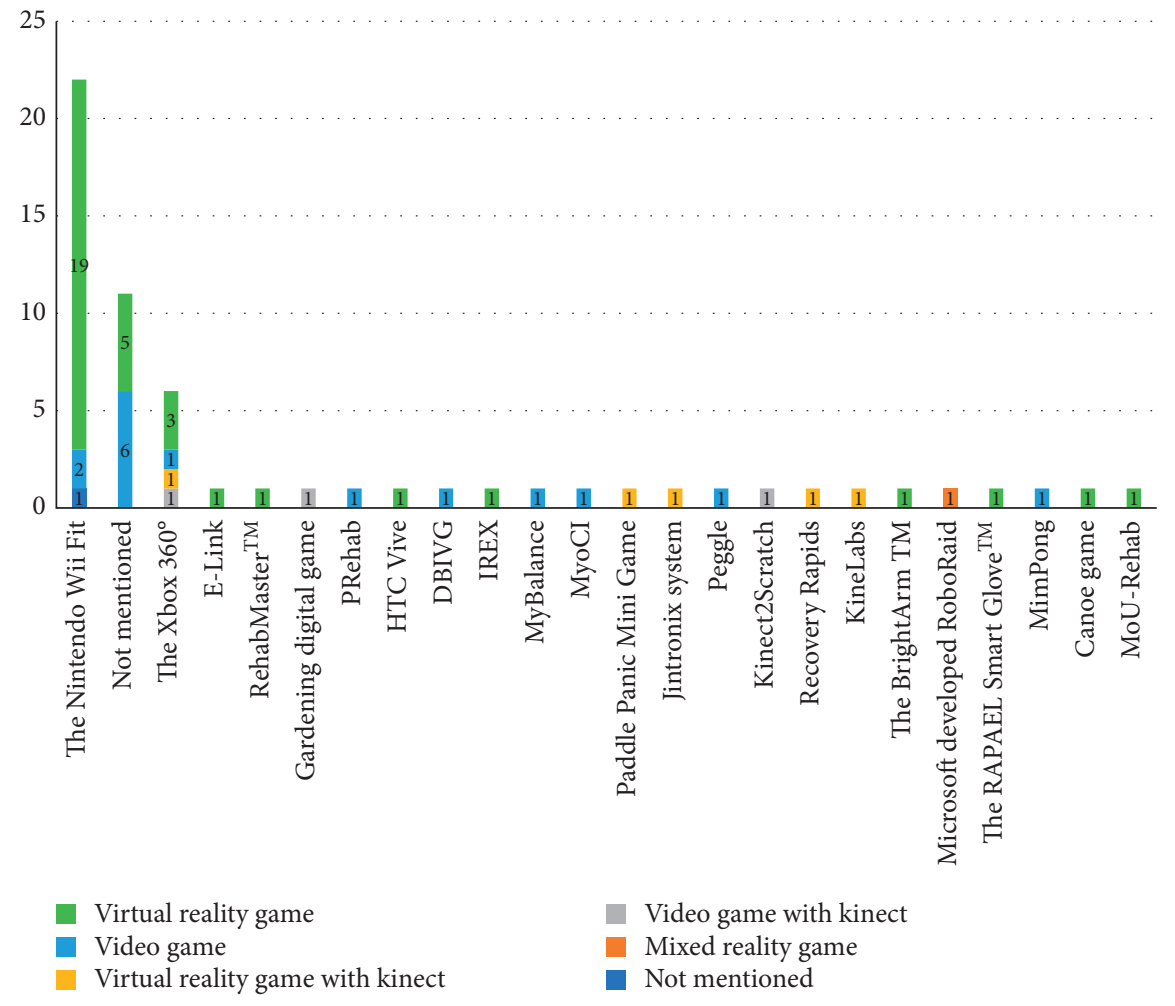

FIGURE 4: The distribution of studies based on type and name of games.

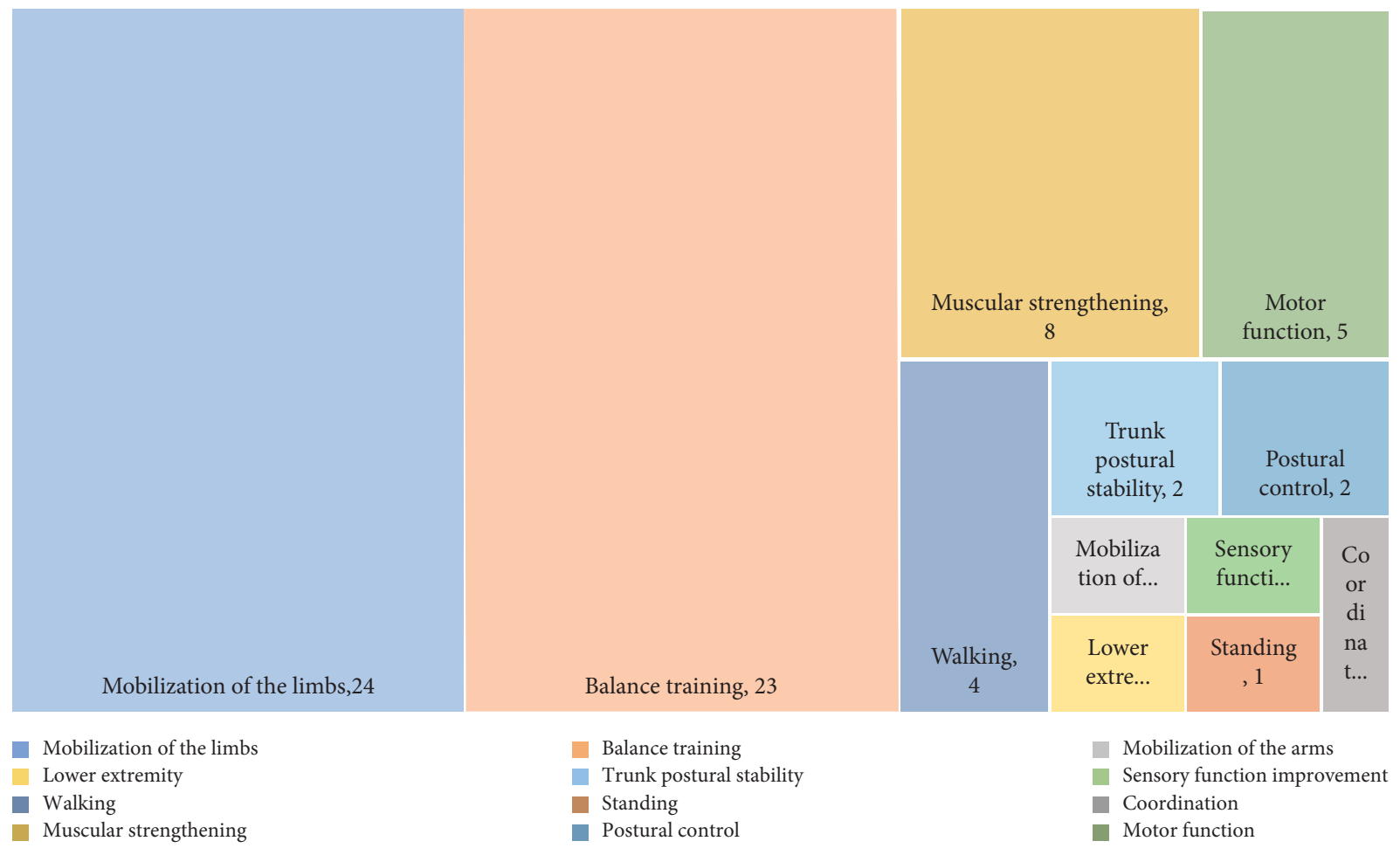

Figure 5: Physical rehabilitation therapies in reviewed studies. 
TABLE 5: Distribution of studies based on the type of study and effectiveness.

\begin{tabular}{lc}
\hline Row labels & Effectiveness \\
\hline Effective & 41 \\
Before and after trial & 13 \\
Nonrandomized clinical trials & 2 \\
RCT & 26 \\
Not effective & 3 \\
RCT & 3 \\
Partly effective & 16 \\
Before and after trial & 3 \\
RCT & 13 \\
Total & 60 \\
\hline
\end{tabular}

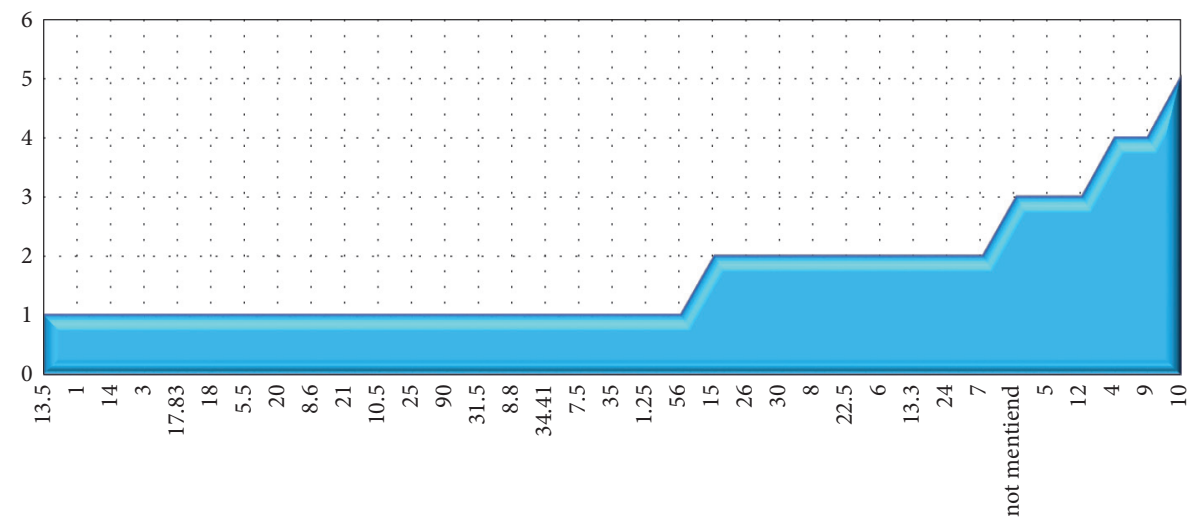

Figure 6: The distribution of studies based on the total time of rehabilitation duration.

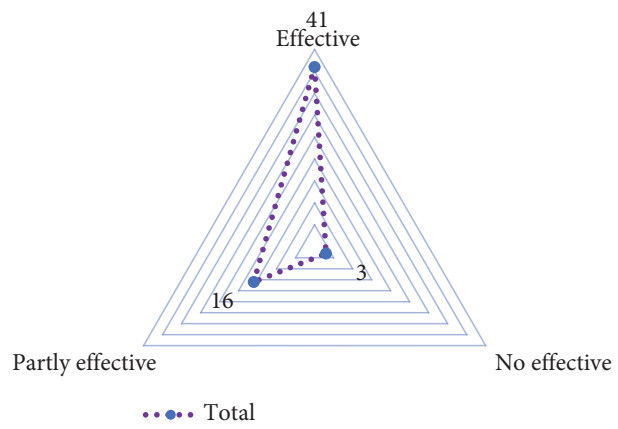

Figure 7: The distribution of the reviewed studies based on effectiveness.

functions. These games increase patients' motivation to perform rehabilitation exercises and provide a pleasant environment for patients, which can lead to more repetition of rehabilitation exercises in these patients [77]. People get feedback while playing virtual reality games, and this factor encourages patients with disabilities to attend therapy sessions and use their remaining functional capacity to succeed in the game [81].

Results have shown that "the Nintendo Wii Fit" games are used more than other games to rehabilitate poststroke patients. Several factors can lead to the most use of this game. Among these factors, we can mention the price of these games, which are relatively inexpensive. These games are widely available to people, and studies have shown that providing an attractive environment increases patients' enjoyment and more repetition of rehabilitation exercises [82-84]. Features of the Wii Fit game system lead to the stimulation of people's interest in continuing to play and can be useful for improving motor function and balance control [61].

Studies showed that the most common use of games in the rehabilitation of stroke survivors was related to limb movement and balance training. In other words, the results of studies that were run to examine the effect of games on people after a stroke had shown these games were effective in improving the balance of people and strengthening the muscles of the limbs [85]. In a systematic review conducted by Corbetta, the effectiveness of virtual reality games has 
been investigated and concluded that managed games have the most significant impact on patient mobility [75]. According to the results of this survey and other studies that show the effect of the game on maintaining balance and movement, it is recommended to use these games in poststroke survivors.

This systematic review had several strengths and limitations. One of the strengths was the use of broad keywords to search in 4 crucial databases. Another strength of this survey was the inclusion of studies presented at conferences. The limitations were the exclusion of articles in non-English language and the time limit imposed on searching databases (from 2014 onwards). Another limitation of this review was the different scales used to measure people's performance, and this factor made it difficult to compare the results of different surveys.

\section{Conclusion}

Game-based approaches lead to patients being able to smoothly perform their rehabilitation movement techniques without going to the treatment centers. These games can immerse the person in the environment by providing virtual or augmented reality capabilities and multiplying the effectiveness of the treatment. Therefore, the use of appropriate technology-based gaming solutions can improve patients' treatment and minimize the waste of time and cost of providing traditional motor rehabilitation. Consequently, these game-based treatments are considered complementary to traditional ones and can reduce the workload of therapists and accelerate the rehabilitation process. Future research should focus on how task-specific game-oriented systems can improve function after stroke, and statistical studies can show this effect more.

\section{Data Availability}

All data generated or analyzed during this study are included within this article.

\section{Conflicts of Interest}

The authors declare that there are no conflicts of interest.

\section{References}

[1] E. Noe-Sebastian, M. Balasch-Bernat, C. Colomer-Font et al., "Disability after stroke: a longitudinal study in moderate and severe stroke patients included in a multidisciplinary rehabilitation program," Revista de Neurologia, vol. 64, no. 9, pp. 385-392, 2017.

[2] V. L. Feigin, M. H. Forouzanfar, R. Krishnamurthi et al., "Global and regional burden of stroke during 1990-2010: findings from the global burden of disease study 2010," The Lancet, vol. 383, no. 9913, pp. 245-255, 2014.

[3] B. B. Gambassi, Efeitos do treinamento resistido dinâmico sobre parâmetros funcionais, autonômicos e de estresse oxidativo em sobreviventes ao acidente vascular cerebral isquêmico crônico, Universidade Estadual de Campinas, Campinas, Brazil, 2018.
[4] P. Astuti, K. Kusnanto, and F. Dwi Novitasari, "Depression and functional disability in stroke patients," Journal of Public Health Research, vol. 9, no. 2, p. 1835, 2020.

[5] N. Takeuchi and S. Izumi, "Rehabilitation with poststroke motor recovery: a review with a focus on neural plasticity," Stroke Research and Treatment, vol. 2013, Article ID 128641, , 2013.

[6] L. Dodakian, A. L. McKenzie, V Le et al., "A home-based telerehabilitation program for patients with stroke," Neurorehabilitation and Neural Repair, vol. 31, no. 10-11, pp. 923-933, 2017.

[7] H. Soufi Ahmadi, A. Hassani Mehraban, M. Amini, and M. Sheikhi, "The effects of virtual reality on upper limb function in chronic stroke patients: a clinical trial," Iranian Rehabilitation Journal, vol. 17, no. 1, pp. 81-89, 2019.

[8] N. Hocine, A. Gouaïch, S. A. Cerri, D. Mottet, J. Froger, and I. Laffont, "Adaptation in serious games for upper-limb rehabilitation: an approach to improve training outcomes," User Modeling and User-Adapted Interaction, vol. 25, no. 1, pp. 65-98, 2015.

[9] H. Leutwyler, E. M. Hubbard, and G. A. Dowling, "Adherence to a videogame-based physical activity program for older adults with schizophrenia," Games for Health Journal, vol. 3, no. 4, pp. 227-233, 2014.

[10] Y.-L. Ng, F. Ma, F. K. Ho, P. Ip, and K.-w. Fu, "Effectiveness of virtual and augmented reality-enhanced exercise on physical activity, psychological outcomes, and physical performance: a systematic review and meta-analysis of randomized controlled trials," Computers in Human Behavior, vol. 99, pp. 278-291, 2019.

[11] B. A. Primack, M. V. Carroll, M. McNamara et al., "Role of video games in improving health-related outcomes," American Journal of Preventive Medicine, vol. 42, no. 6, pp. 630-638, 2012.

[12] J. Simmich, A. J. Deacon, and T. G. Russell, "Active video games for rehabilitation in respiratory conditions: systematic review and meta-analysis," JMIR serious games, vol. 7, no. 1, Article ID e10116, 2019.

[13] H. Tariq, "Effect of balance exercises for person with multiple sclerosis using Wiigame: a systematic review of randomized and non-randomized control trials," Acta Medical International, vol. 3, no. 1, p. 196, 2016.

[14] D. Moher, A. Liberati, J. Tetzlaff, D. G. Altman, and P. Group, "Preferred reporting items for systematic reviews and metaanalyses: the PRISMA statement," PLoS Medicine, vol. 6, no. 7, Article ID e1000097, 2009.

[15] I. Laffont, J. Froger, C. Jourdan et al., "Rehabilitation of the upper arm early after stroke: video games versus conventional rehabilitation. A randomized controlled trial," Annals of Physical and Rehabilitation Medicine, vol. 63, no. 3, pp. 173-180, 2020.

[16] I. Cikajlo, M. Rudolf, R. Mainetti, and N. A. Borghese, "Multiexergames to set targets and supplement the intensified conventional balance training in patients with stroke: a randomized pilot trial," Frontiers in Psychology, vol. 11, p. 572, 2020.

[17] A. C. Glueck and D. Y. Han, "Improvement potentials in balance and visuo-motor reaction time after mixed reality action game play: a pilot study," Virtual Reality, vol. 24, no. 2, pp. 223-229, 2020.

[18] F. Ayoubi, S. Chamouni, O. Zein, and A. R. Sarraj, "Virtual reality movement therapy for post-stroke upper limb rehabilitation trial," in Proceedings of the 2019 Fifth International 
Conference on Advances in Biomedical Engineering (ICABME), pp. 1-3, Piscataway, NJ, USA, October 2019.

[19] J. X. De Gouvêa, D. B. Perez, C. S. Miranda, T. De Paula Oliveira, and M. E. Piemonte, "Upper limb training using virtual reality in patients with chronic sequels of stroke," in Proceedings of the 3rd 2015 Workshop on ICTs for Improving Patients Rehabilitation Research Techniques 2015, pp. 85-88, Lisbon, Portugal, October 2015.

[20] M. J. Cano-Mañas, S. Collado-Vázquez, J. Rodríguez Hernández, A. J. Muñoz Villena, and R. Cano-De-La-Cuerda, "Effects of video-game based therapy on balance, postural control, functionality, and quality of life of patients with subacute stroke: a randomized controlled trial," Journal of Healthcare Engineering, vol. 2020, Article ID 5480315, 11 pages, 2020.

[21] T. T. Şimşek and K. Çekok, "The effects of Nintendo Wii(TM)-based balance and upper extremity training on activities of daily living and quality of life in patients with subacute stroke: a randomized controlled study," International Journal of Neuroscience, vol. 126, no. 12, pp. 1061-1070, 2016.

[22] J. W. Hung, C. X. Chou, Y. J. Chang et al., "Comparison of Kinect2Scratch game-based training and therapist-based training for the improvement of upper extremity functions of patients with chronic stroke: a randomized controlled singleblinded trial," European Journal of Physical and Rehabilitation Medicine, vol. 55, no. 5, pp. 542-550, 2019.

[23] K. Adie, C. Schofield, M. Berrow et al., "Does the use of Nintendo Wii SportsTM improve arm function? Trial of WiiTM in Stroke: a randomized controlled trial and economics analysis," Clinical Rehabilitation, vol. 31, no. 2, pp. 173-185, 2017.

[24] M. A. Ahmad, D. K. A. Singh, N. A. Mohd Nordin, K. Hooi Nee, and N. Ibrahim, "Virtual reality games as an adjunct in improving upper limb function and general health among stroke survivors," International Journal of Environmental Research and Public Health, vol. 16, no. 24, 2019.

[25] Y.-H. Choi, J. Ku, H. Lim, Y. H. Kim, and N.-J. Paik, "Mobile game-based virtual reality rehabilitation program for upper limb dysfunction after ischemic stroke," Restorative Neurology and Neuroscience, vol. 34, no. 3, pp. 455-463, 2016.

[26] H.-S. Choi, W.-S. Shin, D.-H. Bang, and S.-J. Choi, "Effects of game-based constraint-induced movement therapy on balance in patients with stroke: a single-blind randomized controlled trial," American Journal of Physical Medicine \& Rehabilitation, vol. 96, no. 3, pp. 184-190, 2017.

[27] H.-S. Choi, W.-S. Shin, and D.-H. Bang, "Mirror therapy using gesture recognition for upper limb function, neck discomfort, and quality of life after chronic stroke: a singleblind randomized controlled trial," Medical Science Monitor, vol. 25, pp. 3271-3278, 2019.

[28] T. De Paula Oliveira, C. S. Miranda, J. X. M. De Gouvêa, D. B. Perez, A. P. Marques, and M. E. P. Piemonte, "Balance training in virtual reality in patients with chronic sequels of stroke: effects on ICF domains, preliminary data," in Proceedings of the 3rd 2015 Workshop on ICTs for improving Patients Rehabilitation Research Techniques, pp. 96-99, Lisbon, Portugal, October 2015.

[29] N. Givon, G. Zeilig, H. Weingarden, and D. Rand, "Videogames used in a group setting is feasible and effective to improve indicators of physical activity in individuals with chronic stroke: a randomized controlled trial," Clinical Rehabilitation, vol. 30, no. 4, pp. 383-392, 2016.

[30] G. House, G. Burdea, K. Polistico et al., "A rehabilitation firsttournament between teams of nursing home residents with chronic stroke," Games for Health Journal, vol. 5, no. 1, pp. 75-83, 2016.

[31] H.-C. Hsieh, "Training by using an adaptive foot switch and video games to improve balance and mobility following stroke: a randomised controlled trial," Brain Impairment, vol. 20, no. 1, pp. 16-23, 2019.

[32] H.-C. Hsieh, "Use of a gaming platform for balance training after a stroke: a randomized trial," Archives of Physical Medicine and Rehabilitation, vol. 100, no. 4, pp. 591-597, 2019.

[33] L. L. Huang and M. H. Chen, "The effectiveness of gardening game design for the upper extremity function of stroke patients," in Proceedings of the 2016 International Conference on Advanced Materials for Science and Engineering (ICAMSE), Tainan, China, November 2016.

[34] R. U. Khan, M. W. Tahir, and M. I. Tiwana, "Rehabilitation process of upper limbs muscles through EMG based video game," in Proceedings of the 2019 International Conference on Robotics and Automation in Industry (ICRAI), pp. 1-5, IEEE, Piscataway, NJ, USA, October 2019.

[35] S. Ikbali Afsar, I. Mirzayev, O. Umit Yemisci, and S. N. Cosar Saracgil, "Virtual reality in upper extremity rehabilitation of stroke patients: a randomized controlled trial," Journal of Stroke and Cerebrovascular Diseases, vol. 27, no. 12, pp. 3473-3478, 2018.

[36] M.-M. Lee, D.-C. Shin, and C.-H. Song, "Canoe game-based virtual reality training to improve trunk postural stability, balance, and upper limb motor function in subacute stroke patients: a randomized controlled pilot study," Journal of Physical Therapy Science, vol. 28, no. 7, pp. 2019-2024, 2016.

[37] M. Serper, A. W. Cubell, M. E. Deleener et al., "Telemedicine in liver disease and beyond: can the COVID-19 crisis lead to action?" Hepatology, vol. 72, no. 2, pp. 723-728, 2020.

[38] S. H. Lee, H. Y. Jung, S. J. Yun, B. M. Oh, and H. G. Seo, "Upper extremity rehabilitation using fully immersive virtual reality games with a head mount display: a feasibility study," PM\&R: The Journal of Injury, Function, and Rehabilitation, vol. 12, no. 3, pp. 257-262, 2020.

[39] P. A. McNulty, A. G. Thompson-Butel, S. G. Faux et al., "The efficacy of Wii-based movement therapy for upper limb rehabilitation in the chronic poststroke period: a randomized controlled trial," International Journal of Stroke, vol. 10, no. 8, pp. 1253-1260, 2015.

[40] S. M. Nijenhuis, G. B. Prange-Lasonder, A. H. Stienen, J. S. Rietman, and J. H. Buurke, "Effects of training with a passive hand orthosis and games at home in chronic stroke: a pilot randomised controlled trial," Clinical Rehabilitation, vol. 31, no. 2, pp. 207-216, 2017.

[41] K. Paquin, S. Ali, K. Carr, J. Crawley, C. McGowan, and S. Horton, "Effectiveness of commercial video gaming on fine motor control in chronic stroke within community-level rehabilitation," Disability \& Rehabilitation, vol. 37, no. 23, pp. 2184-2191, 2015.

[42] E. Pedreira da Fonseca, N. M. Ribeiro da Silva, and E. B. Pinto, "Therapeutic effect of virtual reality on post-stroke patients: randomized clinical trial," Journal of Stroke and Cerebrovascular Diseases, vol. 26, no. 1, pp. 94-100, 2017.

[43] D. Rand, H. Weingarden, R. Weiss et al., "Self-training to improve UE function at the chronic stage post-stroke: a pilot randomized controlled trial," Disability \& Rehabilitation, vol. 39, no. 15, pp. 1541-1548, 2017.

[44] J.-H. Shin, S. Bog Park, and S. Ho Jang, "Effects of game-based virtual reality on health-related quality of life in chronic stroke patients: a randomized, controlled study," Computers in Biology and Medicine, vol. 63, pp. 92-98, 2015. 
[45] J. H. Shin, M. Y. Kim, J. Y. Lee et al., "Effects of virtual realitybased rehabilitation on distal upper extremity function and health-related quality of life: a single-blinded, randomized controlled trial," Journal of NeuroEngineering and Rehabilitation, vol. 13, no. 1, p. 17, 2016.

[46] P. Standen, K. Threapleton, A. Richardson et al., "A low cost virtual reality system for home based rehabilitation of the arm following stroke: a randomised controlled feasibility trial," Clinical Rehabilitation, vol. 31, no. 3, pp. 340-350, 2017.

[47] D. Rand, A. Yacoby, R. Weiss, S. Reif, R. Malka, and H. Weingarden, Home-based Self-Training Using VideoGames: Preliminary Data from a Randomised Controlled Trial2015.

[48] A. I. R. Kottink, G. B. Prange, T. Krabben, J. S. Rietman, and J. H. Buurke, "Gaming and conventional exercises for improvement of arm function after stroke: a randomized controlled pilot study," Games for Health Journal, vol. 3, no. 3, pp. 184-191, 2014.

[49] D. Rand, N. Givon, H. Weingarden, A. Nota, and G. Zeilig, "Eliciting upper extremity purposeful movements using video games: a comparison with traditional therapy for stroke rehabilitation," Neurorehabilitation and Neural Repair, vol. 28, no. 8, pp. 733-739, 2014.

[50] K. Jordan, M. Sampson, and M. King, "Gravity-supported exercise with computer gaming improves arm function in chronic stroke," Archives of Physical Medicine and Rehabilitation, vol. 95, no. 8, pp. 1484-1489, 2014.

[51] S. C. Fan, F. C. Su, S. S. Chen, W. H. Hou, J. S. Sun, and K. H. Chen, "Improved intrinsic motivation and muscle activation patterns in reaching task using virtual reality training for stroke rehabilitation: a pilot randomized control trial," Journal of Medical and Biological Engineering, vol. 34, no. 4, pp. 399-407, 2014.

[52] D. McEwen, A. Taillon-Hobson, M. Bilodeau, H. Sveistrup, and H. Finestone, "Virtual reality exercise improves mobility after stroke," Stroke, vol. 45, no. 6, pp. 1853-1855, 2014.

[53] J.-W. Hung, C.-X. Chou, Y.-W. Hsieh et al., "Randomized comparison trial of balance training by using exergaming and conventional weight-shift therapy in patients with chronic stroke," Archives of Physical Medicine and Rehabilitation, vol. 95, no. 9, pp. 1629-1637, 2014.

[54] N. Norouzi-Gheidari, A. Hernandez, P. S. Archambault, J. Higgins, L. Poissant, and D. Kairy, "Feasibility, safety and efficacy of a virtual reality exergame system to supplement upper extremity rehabilitation post-stroke: a pilot randomized clinical trial and proof of principle," International Journal of Environmental Research and Public Health, vol. 17, no. 1, 2019.

[55] A. Aşkın, E. Atar, H. Koçyiğit, and A. Tosun, "Effects of Kinect-based virtual reality game training on upper extremity motor recovery in chronic stroke," Somatosensory \& Motor Research, vol. 35, no. 1, pp. 25-32, 2018.

[56] C. S. Miranda, T. d. P. Oliveira, J. X. M. Gouvêa, D. B. Perez, A. P. Marques, and M. E. P. Piemonte, "Balance training in virtual reality promotes performance improvement but not transfer to postural control in people with chronic stroke," Games for Health Journal, vol. 8, no. 4, pp. 294-300, 2019.

[57] A. B. G. S. Fernandes, J. Oliveira dos Passos, D. Paiva de Brito, and T. Fernandes Campos, "Comparison of the immediate effect of the training with a virtual reality game in stroke patients according side brain injury," NeuroRehabilitation, vol. 35, no. 1, pp. 39-45, 2014.

[58] G. Morone, M. Tramontano, M. Iosa et al., "The efficacy of balance training with video game-based therapy in subacute stroke patients: a randomized controlled trial," BioMed Research International, vol. 2014, Article ID 580861, 6 pages, 2014.

[59] F. Noveletto, A. V. Soares, F. L. F. Eichinger, S. C. Domenech, M. d. S. Hounsell, and P. B. Filho, "Biomedical serious game system for lower limb motor rehabilitation of hemiparetic stroke patients," IEEE Transactions on Neural Systems and Rehabilitation Engineering, vol. 28, no. 6, pp. 1481-1487, 2020.

[60] V. A. dos Santos, M. D. Santos, N. M. D. Ribeiro, and I. L. Maldonado, "Combining proprioceptive neuromuscular facilitation and virtual reality for improving sensorimotor function in stroke survivors: a randomized clinical trial," Journal of Central Nervous System Disease, vol. 11, 2019.

[61] D. Choi, W. Choi, and S. Lee, "Influence of nintendo wii fit balance game on visual perception, postural balance, and walking in stroke survivors: a pilot randomized clinical trial," Games for Health Journal, vol. 7, no. 6, pp. 377-384, 2018.

[62] A. L. Borstad, R. Crawfis, K. Phillips et al., "In-Home delivery of constraint-induced movement therapy via virtual reality gaming," Journal of Patient-Centered Research and Reviews, vol. 5, no. 1, pp. 6-17, 2018.

[63] F. Noveletto, A. V. Soares, B. A. Mello et al., "Biomedical serious game system for balance rehabilitation of hemiparetic stroke patients," IEEE Transactions on Neural Systems and Rehabilitation Engineering, vol. 26, no. 11, pp. 2179-2188, 2018.

[64] A. A. Carregosa, L. R. Aguiar dos Santos, M. R. Masruha et al., "Virtual rehabilitation through nintendo wii in poststroke patients: follow-up," Journal of Stroke and Cerebrovascular Diseases, vol. 27, no. 2, pp. 494-498, 2018.

[65] J.-H. Park and J.-H. Park, "The effects of game-based virtual reality movement therapy plus mental practice on upper extremity function in chronic stroke patients with hemiparesis: a randomized controlled trial," Journal of Physical Therapy Science, vol. 28, no. 3, pp. 811-815, 2016.

[66] K. J. Bower, R. A. Clark, J. L. McGinley, C. L. Martin, and K. J. Miller, "Clinical feasibility of the Nintendo Wii for balance training post-stroke: a phase II randomized controlled trial in an inpatient setting," Clinical Rehabilitation, vol. 28, no. 9, pp. 912-923, 2014.

[67] E. V. Donoso Brown, S. W. McCoy, A. S. Fechko, R. Price, T. Gilbertson, and C. T. Moritz, "Preliminary investigation of an electromyography-controlled video game as a home program for persons in the chronic phase of stroke recovery," Archives of Physical Medicine and Rehabilitation, vol. 95, no. 8, pp. 1461-1469, 2014.

[68] A. Slijper, K. E. Svensson, P. Backlund, H. Engström, and K. S. Sunnerhagen, "Computer game-based upper extremity training in the home environment in stroke persons: a single subject design," Journal of NeuroEngineering and Rehabilitation, vol. 11, p. 35, 2014.

[69] C. Chen, S. Lee, W. Wang, H. Chen, J. Liu, and Y. Huang, "The changes of improvement-related motor kinetics after virtual reality based rehabilitation," in Proceedings of the 2017 International Conference on Applied System Innovation (ICASI), Sapporo, Japan, May 2017.

[70] M. M. Lee, K. J. Lee, and C. H. Song, "Game-based virtual reality canoe paddling training to improve postural balance and upper extremity function: a preliminary randomized controlled study of 30 patients with subacute stroke," Medical Science Monitor, vol. 24, pp. 2590-2598, 2018.

[71] D.-S. Park, D.-G. Lee, K. Lee, and G. Lee, "Effects of virtual reality training using xbox kinect on motor function in stroke 
survivors: a preliminary study," Journal of Stroke and Cerebrovascular Diseases, vol. 26, no. 10, pp. 2313-2319, 2017.

[72] J.-S. Park, G. Lee, J.-B. Choi, N.-K. Hwang, and Y.-J. Jung, "Game-based hand resistance exercise versus traditional manual hand exercises for improving hand strength, motor function, and compliance in stroke patients: a multi-center randomized controlled study," NeuroRehabilitation, vol. 45, no. 2, pp. 221-227, 2019.

[73] H. Soufi Ahmadi, A. Hassani Mehraban, M. Amini, and M. Sheikhi, "The effects of virtual reality on upper limb function in chronic stroke patients: a clinical trial," Iranian Rehabilitation Journal, vol. 17, no. 1, pp. 81-89, 2019.

[74] M. de Castro-Cros, M. Sebastian-Romagosa, J. RodríguezSerrano, E. Opisso, M. Ochoa, and R. Ortner, "Effects of gamification in BCI functional rehabilitation," Frontiers in Neuroscience, vol. 14, 2020.

[75] D. Corbetta, F. Imeri, and R. Gatti, "Rehabilitation that incorporates virtual reality is more effective than standard rehabilitation for improving walking speed, balance and mobility after stroke: a systematic review," Journal of Physiotherapy, vol. 61, no. 3, pp. 117-124, 2015.

[76] S. M. Nijenhuis, G. B. Prange-Lasonder, A. H. Stienen, J. S. Rietman, and J. H. Buurke, "Effects of training with a passive hand orthosis and games at home in chronic stroke: a pilot randomised controlled trial," Clinical Rehabilitation, vol. 31, no. 2, pp. 207-216, 2017.

[77] L. Sheehy, A. Taillon-Hobson, H. Sveistrup et al., "Does the addition of virtual reality training to a standard program of inpatient rehabilitation improve sitting balance ability and function after stroke? Protocol for a single-blind randomized controlled trial," BMC Neurology, vol. 16, no. 1, p. 42, 2016.

[78] L. Tao, C. Yin, X. Zhou, and J. Liu, "Design and implementation of an interactive hand rehabilitation training system based on LabVIEW," in Proceedings of the 2020 12th International Conference on Intelligent Human-Machine Systems and Cybernetics (IHMSC), Las Vegas, NV, USA, August 2020.

[79] A. S. Ahuja, "Should RCT's be used as the gold standard for evidence based medicine?" Integrative medicine research, vol. 8, no. 1, pp. 31-32, 2019.

[80] A. Leinonen, M. Koponen, and S. Hartikainen, "Systematic review: representativeness of participants in RCTs of acetylcholinesterase inhibitors," PLoS One, vol. 10, no. 5, Article ID e0124500, 2015.

[81] J. Dascal, M. Reid, W. W. IsHak et al., "Virtual reality and medical inpatients: a systematic review of randomized, controlled trials," Innovations in clinical neuroscience, vol. 14, no. 1-2, pp. 14-21, 2017.

[82] N. B. Herz, S. H. Mehta, K. D. Sethi, P. Jackson, P. Hall, and J. C. Morgan, "Nintendo Wii rehabilitation ("Wii-hab") provides benefits in Parkinson's disease," Parkinsonism \& Related Disorders, vol. 19, no. 11, pp. 1039-1042, 2013.

[83] D. Tarakci, A. R. Ozdincler, E. Tarakci, F. Tutuncuoglu, and M. Ozmen, "Wii-based balance therapy to improve balance function of children with cerebral palsy: a pilot study," Journal of Physical Therapy Science, vol. 25, no. 9, pp. 1123-1127, 2013.
[84] V. P. Nicholson, M. McKean, J. Lowe, C. Fawcett, and B. Burkett, "Six weeks of unsupervised Nintendo Wii Fit gaming is effective at improving balance in independent older adults," Journal of Aging and Physical Activity, vol. 23, no. 1, pp. 153-158, 2015.

[85] A. L. Betker, A. Desai, C. Nett, N. Kapadia, and T. Szturm, "Game-based exercises for dynamic short-sitting balance rehabilitation of people with chronic spinal cord and traumatic brain injuries," Physical Therapy, vol. 87, no. 10, pp. 1389-1398, 2007. 